\title{
Influence of climate change and prescribed fire on habitat suitability and abundance of the high-elevation endemic Cow Knob Salamander (Plethodon punctatus)
}

\author{
Carl David Jacobsen \\ cdj0015@mix.wvu.edu
}

Follow this and additional works at: https://researchrepository.wvu.edu/etd

Part of the Biology Commons, Forest Management Commons, Population Biology Commons, and the Terrestrial and Aquatic Ecology Commons

\footnotetext{
Recommended Citation

Jacobsen, Carl David, "Influence of climate change and prescribed fire on habitat suitability and abundance of the high-elevation endemic Cow Knob Salamander (Plethodon punctatus)" (2019). Graduate Theses, Dissertations, and Problem Reports. 4051.

https://researchrepository.wvu.edu/etd/4051

This Thesis is protected by copyright and/or related rights. It has been brought to you by the The Research Repository @ WVU with permission from the rights-holder(s). You are free to use this Thesis in any way that is permitted by the copyright and related rights legislation that applies to your use. For other uses you must obtain permission from the rights-holder(s) directly, unless additional rights are indicated by a Creative Commons license in the record and/ or on the work itself. This Thesis has been accepted for inclusion in WVU Graduate Theses, Dissertations, and Problem Reports collection by an authorized administrator of The Research Repository @ WVU. For more information, please contact researchrepository@mail.wvu.edu.
} 
Influence of climate change and prescribed fire on habitat suitability and abundance of the high-elevation endemic Cow Knob Salamander (Plethodon punctatus)

\author{
Carl D. Jacobsen
}

Thesis submitted to the Davis College of Agriculture, Natural Resources, and Design

At West Virginia University

in partial fulfillment of the requirements for the degree of

Master of Science

in Wildlife and Fisheries Resources

Donald J. Brown, Ph.D., Chair

Jamie L. Schuler, Ph.D.

Thomas M. Schuler, Ph.D.

Division of Forestry and Natural Resources

\author{
Morgantown, West Virginia
}

2019

Keywords: Cow Knob Salamander (Plethodon punctatus), woodland salamanders, amphibians, climate change, habitat suitability model, prescribed fire, forest management (C) 2019 Carl D. Jacobsen 


\begin{abstract}
Influence of climate change and prescribed fire on habitat suitability and abundance of the highelevation endemic Cow Knob Salamander (Plethodon punctatus)
\end{abstract}

Carl D. Jacobsen

Amphibians are facing global declines due to climate change, loss and degradation of habitat, invasive species, and disease. The Appalachian region of the eastern USA is a global biodiversity hotspot for salamanders, which are considered keystone species that influence nutrient dynamics in terrestrial and aquatic food webs. There are high rates of salamander endemism in the Appalachian region, with many species restricted to isolated, high elevation areas. The Cow Knob Salamander (Plethodon punctatus) is one such species. It is only found at elevations >675 m (most populations are above $900 \mathrm{~m}$ ) on Shenandoah Mountain, North Mountain, and Nathaniel Mountain in the Valley and Ridge Province in eastern West Virginia and Virginia. A recent study found that $P$. punctatus may be one of the most vulnerable species of Appalachian salamander to climate change due to its narrow distribution and poor ability to acclimate to warmer temperatures. However, little research has been conducted on P. punctatus, and information is needed by land managers to guide habitat and species management actions. The purpose of my thesis was to quantify the influence of broad and fine-scale habitat characteristics and assess the influence of climate change and active habitat management using prescribed fire, on the distribution and abundance of $P$. punctatus. 
In chapter 1, I provide background information on the causes of amphibian declines globally and in the Appalachian region, and information on the biology and conservation status of $P$. punctatus. I also summarize the goals of this research and give a summary of chapter topics.

In chapter 2, I created habitat suitability models to examine the climatic and geological factors contributing to the distribution of $P$. punctatus. I also projected mid and end-of-century changes in habitat suitability as the climate warms. I found that the distribution of $P$. punctatus is largely driven by variables that contribute to a cool, moist climate. Elevation, heat load index, slope, hillshade, and mean annual temperature largely explain where this species is found. I projected that the climatic niche for $P$. punctatus will mostly disappear by mid-century, with a continual decrease through the year 2100. However, I identified areas of climate refugia that may, at least temporarily, allow for the persistence of this species.

In chapter 3, I examined the influence of forest characteristics and habitat management using prescribed fire on terrestrial salamanders on Shenandoah Mountain. I surveyed salamanders in 4 burn units that differed in burn history as well as adjacent control areas, using nighttime visual encounter surveys and cover board surveys. I compared the response of $P$. punctatus with the more common and widespread Eastern Red-Backed Salamander (Plethodon cinereus). I found that areas that have more talus, are on the west side of Shenandoah Mountain, and have higher canopy cover had a higher abundance of $P$. punctatus and $P$. cinereus. Abundance was lower for $P$. punctatus in burned areas, but I was unable to draw conclusions about burn severity. A high-severity burn was negatively correlated with $P$. cinereus abundance, but there was not a significant effect for low-severity burns. 
My findings in Chapter 2 are consistent with previous studies that project $P$. punctatus will lose most of its climatic niche by the end of the $21^{\text {st }}$ century. The results of Chapter 3 indicate potential short-term negative impacts of prescribed fire on woodland salamanders in central Appalachia, particularly when burning results in reduced canopy cover. This thesis contributes to the general ecological knowledge for $P$. punctatus and provides land managers with information that can be used for proactive conservation of the species. 


\section{ACKNOWLEDGMENTS}

I thank the U.S. Forest Service Northern Research Station for providing funding for my project, and the George Washington-Jefferson National Forest staff for their assistance in study design and logistics. I thank William Flint for his insights into the ecology of Plethodon punctatus, and for sharing his location data, which made Chapter 2 possible and helped with planning for Chapter 3. I thank my advisor Donald Brown for his assistance in analyzing data and writing, challenging me intellectually, and for pushing me to make this thesis the best version possible. I thank my committee members Jamie Schuler and Thomas Schuler for their insights into forestry and the effects of prescribed fire. I also thank Christopher Rota and Michael Strager for their excellent instruction and help learning statistical and spatial methods. I thank my labmates Sarah Crayton and Lacy Rucker for their assistance in the field and with statistical analyses. I thank all my friends and family who have provided me support through challenging times, especially Melissa, Stephen, Jennifer, Grannie Annie, Aunt Pam, and my dad. I want to give a special thanks to my mom for her unconditional love and support, and for always being there for me. 


\section{TABLE OF CONTENTS}

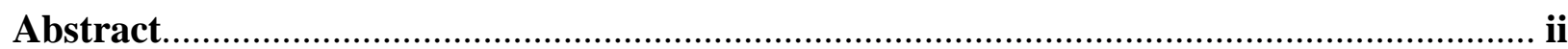

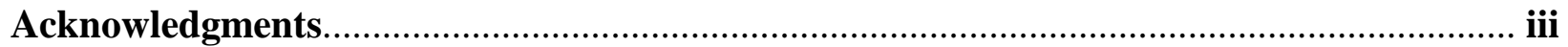

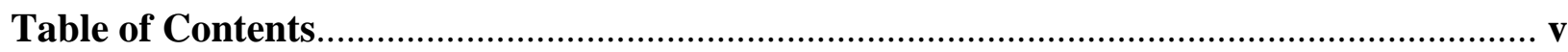

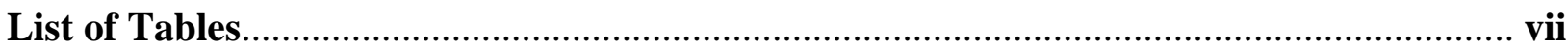

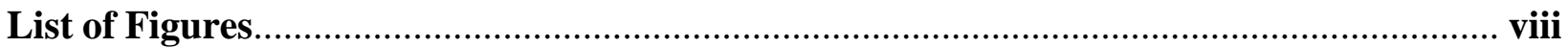

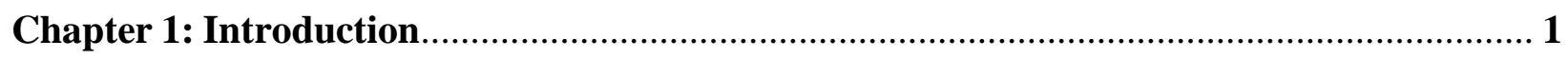

1. Amphibian Conservation in the Appalachians.......................................................... 1

2. The Cow Knob Salamander (Plethodon punctatus) ……………………………....... 2

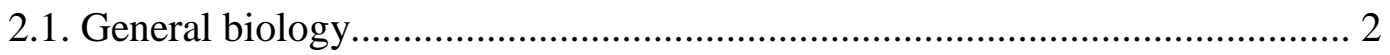

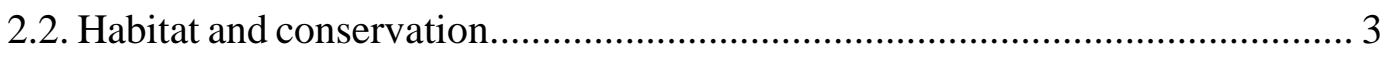

2.3. Climate change............................................................................................... 4

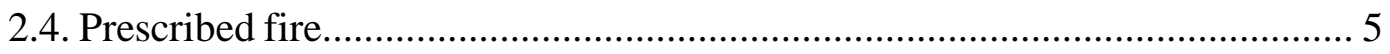

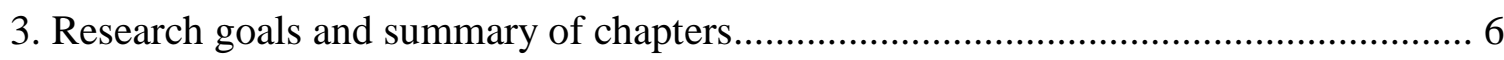

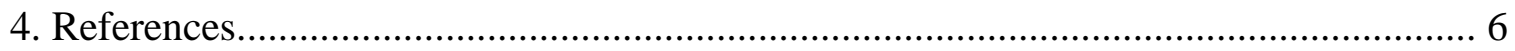

Chapter 2. Vulnerability of high-elevation endemic salamanders to climate change: a case study with the Cow Knob Salamander (Plethodon punctatus) …………………............... 12

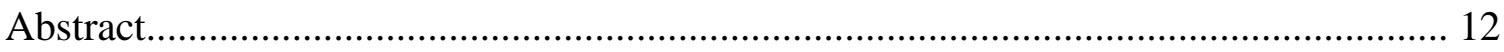

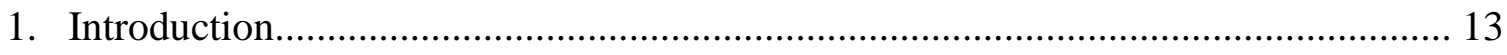

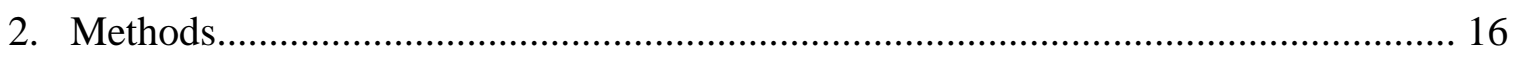

2.1. Species occurrence data and study area............................................................. 16

2.2. Modeling overview................................................................................... 16

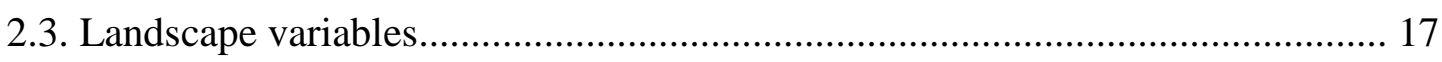

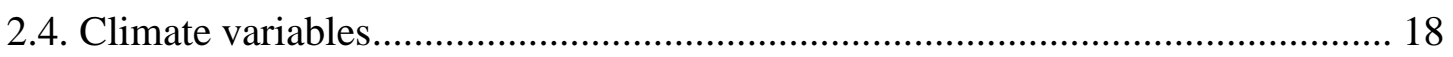

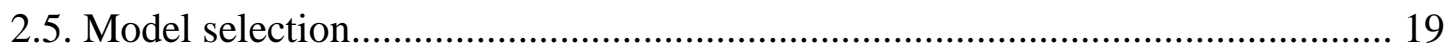

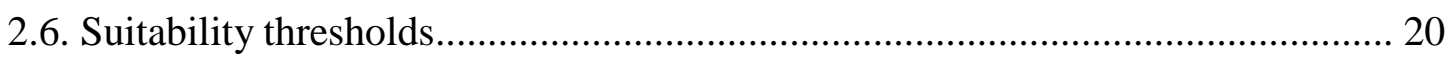

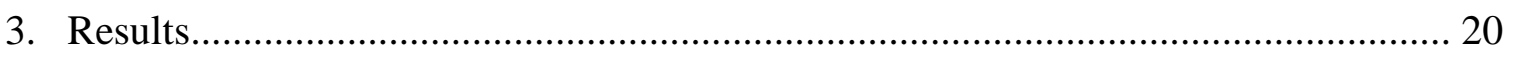

3.1. Landscape model.................................................................................. 20

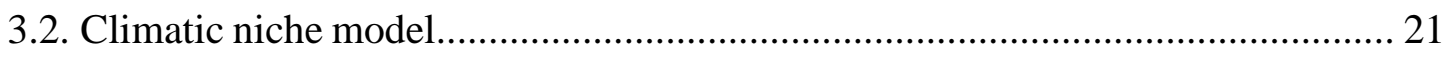




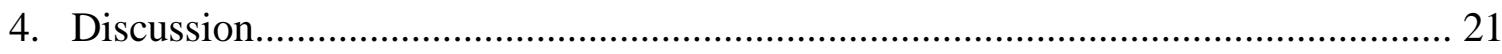

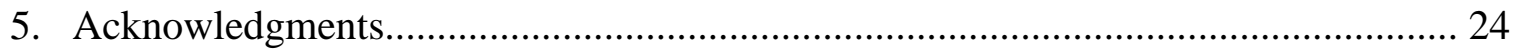

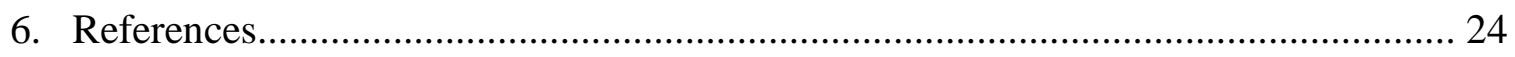

Chapter 3. Influence of prescribed fire and forest structure on woodland salamander

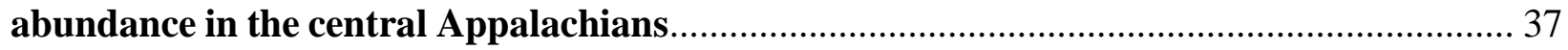

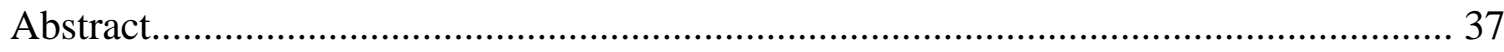

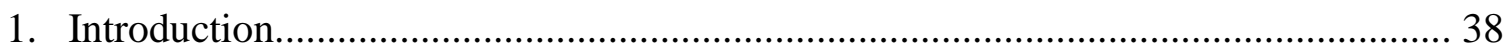

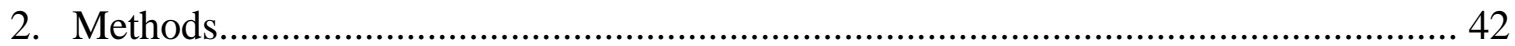

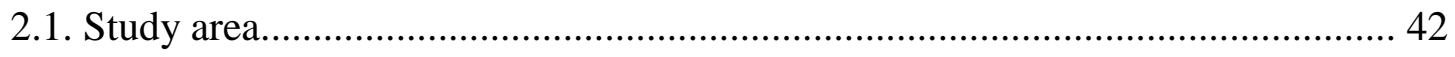

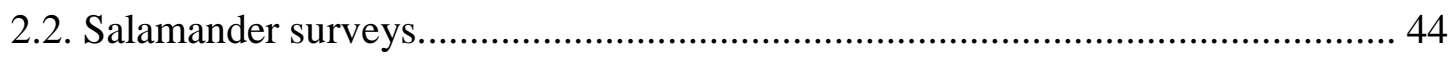

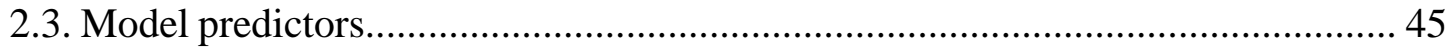

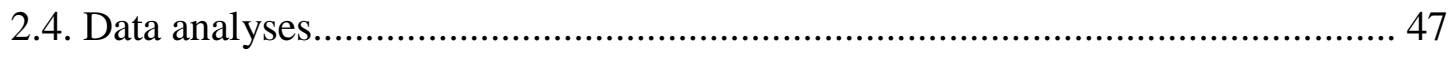

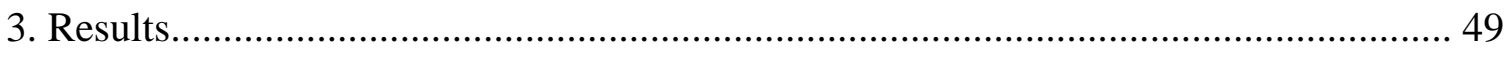

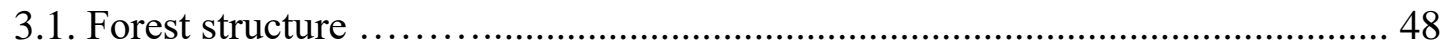

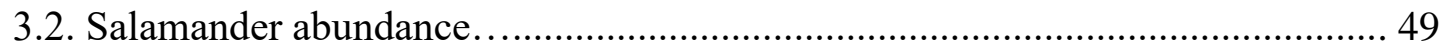

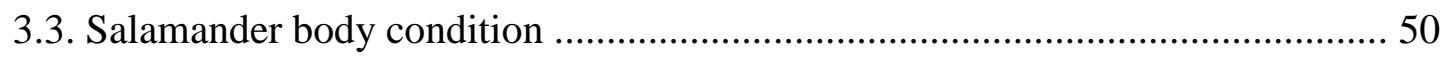

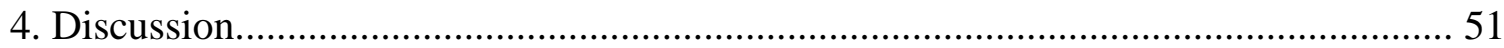

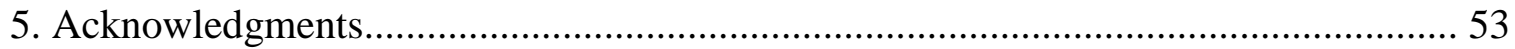

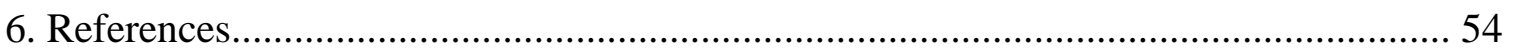




\section{LIST OF TABLES}

Table 2-1. Variables considered (left) and used (right) for modeling the occurrence of the Cow Knob Salamander (Plethodon punctatus) across the species' distribution in eastern West Virginia and western Virginia, USA. All variables were standardized using a Z-score transformation prior

to analyses. 31

Table 2-2. Model selection results to determine the optimal habitat suitability models for explaining the correlation between environmental variables and Cow Knob Salamander (Plethodon punctatus) occurrence across the species' distribution in eastern West Virginia and western Virginia, USA. The landscape models (left) consisted of topographic variables, while the climate niche models (right) consisted of climate and climate refugia variables. Variables included elevation (Elev), hillshade (Hill), heat load index (HLI), slope (Slp), topographical position index (TPI), mean annual temperature (AT), precipitation in the warmest quarter (Pwarm), precipitation in the wettest quarter (Pwet), temperature seasonality (TS). Model selection was based on Akaike's Information Criterion corrected for small sample size (AIC $c) .32$

Table 2-3. Parameter estimates $(\beta)$ and standard errors (SE) from the best approximating landscape model (left) and climate niche model (right) explaining the correlation between habitat variables and Cow Knob Salamander (Plethodon punctatus) occurrence across the species' distribution in eastern West Virginia and western Virginia, USA.

Table 2-4. Summary statistics for projected changes in mean annual temperature, and resulting percentage changes in species occurrence probability classes for the Cow Knob Salamander (Plethodon punctatus) across the species' distribution in eastern West Virginia and western Virginia, USA. Low occurrence probability habitat is defined by the minimum training presence threshold, where all known locations were correctly predicted by the model, while high occurrence probability habitat is defined by probability values that are above the 10 fixed cumulative (i.e. the value that results in a $10 \%$ omission in training data).

Table 3-1. Model selection results to determine relationships between fire history and habitat characteristics on Cow Knob Salamander (Plethodon punctatus) and Red-backed Salamander (Plethodon cinereus) abundance. Geological-topographic model selection variables included state (i.e. West Virginia $=1$, or Virginia =0), elevation $($ Elev), slope, hillshade (Hill), Heat Load Index (HLI), an index of talus cover (Talus), and talus or not talus (Bin_tal). Fire history model selection variables included unburned or burned (Burn Status), unburned and severity of burns (Burn Class), and time-since-burn (Time burn). Forest structure model selection variables included canopy cover (C\%), vegetation cover (V\%), leaf cover ( $\mathrm{L} \%)$, moss cover (M\%), and litter depth in cm (LD). Model selection was based on Quasi Akaike's Information Criterion corrected for small sample size $(\mathrm{QAIC} c)$ 
Table 3-2. Abundance parameter estimates $(\beta)$ for the best approximating fire history and forest structure $N$-mixture models for the Cow Knob Salamander (Plethodon punctatus; left) and the Eastern Red-Backed Salamander (Plethodon cinereus; right). Variables include state (West Virginia or Virginia), an index of talus cover (Talus), talus or not talus (Bin_tal), canopy cover (C\%), vegetation cover (V\%), litter depth (LD), unburned or burned (Burn Status), and burn class (i.e. unburned, low-severity [Low] or high-severity [High]).............................................. 63

Table 3-3. Model selection results for relationships between habitat variables and body condition index (BCI) for the Cow Knob Salamander (Plethodon punctatus; left) and Eastern Red-Backed Salamander (Plethodon cinereus; right). Geological-topographic model selection variables included state (West Virginia or Virginia), an index of talus cover (Talus), elevation (Elev), slope, hillshade (Hill), and Heat Load Index (HLI). Fire history model selection variables included unburned or burned (Burn Status), and unburned and severity of burns (Burn Class). Forest structure model selection variables included canopy cover (C\%), vegetation cover (V\%), leaf cover (L\%), moss cover (M\%), and litter depth (LD). Model selection was based on Quasi Akaike's Information Criterion corrected for small sample size $\left(\mathrm{AIC}_{c}\right)$

Table 3-4. Parameter estimates $(\beta)$ for relationships between habitat variables and body condition index (BCI) for the Cow Knob Salamander (Plethodon punctatus; left) and Eastern Red-Backed Salamander (Plethodon cinereus; right). Geological-topographic variables include state (West Virginia or Virginia) and slope, fire history variables include unburned or burned (Burn Status), and forest structure variables include vegetation cover $(\mathrm{V} \%)$, leaf cover $(\mathrm{L} \%)$, and litter depth (LD) 


\section{LIST OF FIGURES}

Figure 1-1. Picture of the Cow Knob Salamander (Plethodon punctatus), in moss-covered talus habitat. Plethodon punctatus superficially resembles Slimy Salamanders (Plethodon glutinosus complex), but it has more webbing between its toes and a lighter colored throat.

Figure 2-1. A) General contemporary distribution map for the Cow Knob Salamander (Plethodon punctatus) along the West Virginia and Virginia border in the Valley and Ridge Province, USA. B) Projected contemporary occurrence probability for the Cow Knob Salamander based on the top landscape model that used the additive effects elevation, heat load index (HLI), hillshade, and slope. C) Projected contemporary occurrence probability for the Cow Knob Salamander based on the top climate niche model that used the additive effects of mean annual temperature, HLI, and hillshade

Figure 2-2. Map of climate refugia (high occurrence probability habitat [dark shaded areas]) for the Cow Knob Salamander (Plethodon punctatus) in the year 2100 using the median of an ensemble of 31 climate models under the 4.5 representative concentration pathway (RCP) scenario that forces a gradual reduction in greenhouse gas emissions after the year 2030. This climatic niche model used the additive effects of mean annual temperature, HLI (heat load index), and hillshade.

Figure 3-1. Burn units included in this study investigating responses of woodland salamanders to prescribed fire management on Shenandoah Mountain in the George Washington National Forest in West Virginia and Virginia, USA. Prescribed burns were conducted in the following years: North New Road (NNR) in 2012 and 2015, Little Fork (LF) in 2000 and 2008, Hone Quarry (HQ) in 1999, 2002, 2010, 2013, and 2018, and Hone Quarry 2 (HQ2) in 2013 and 2018.

Figure 3-2. Biplots from redundancy analyses (RDA) showing the relationships between forest structure characteristics and fire history variables at our woodland salamander survey plots on Shenandoah Mountain in the George Washington National Forest in West Virginia and Virginia, USA. Forest structure characteristics included canopy cover \% (Canopy), moss cover \% (MossC), vegetation cover \% (VegC), leaf cover \% (LeafC), and leaf litter depth (LitterD). (A) Relationships between forest structure characteristics and whether a site was located in the unburned, low-severity (Low), or high-severity (High) burn class. (B) Relationships between forest structure characteristics and time-since-burn (BurnT) among the burn sites. Forest structure characteristics pointing towards the fire history variables were positively correlated, and vice versa. 
Figure 3-3. Estimated relationship between air temperature and detection probability $(p)$ for (A) the Cow Knob Salamander (Plethodon punctatus), and (B) the Eastern Red-Backed Salamander (Plethodon cinereus) on Shenandoah Mountain in the George Washington National Forest. These $p$ estimates are based on $N$-mixture models that included 197 surveys across 61 sites in 2017 and 2018, abundance predictors were (West Virginia or Virginia), talus or not talus, and canopy cover (\%) for $P$. punctatus and state, canopy cover (\%), and vegetation cover (\%) for $P$. cinereus. The black line represents mean detection probability and gray areas fall within the $95 \%$ confidence interval.

Figure 3-4. Estimated abundances of (A) the Cow Knob Salamander (Plethodon punctatus) and (B) the Eastern Red-backed Salamander (Plethodon cinereus) across $61,25 \mathrm{~m}^{2}$ sites surveyed in 2017 or 2018 on Shenandoah Mountain in the George Washington National Forest in West Virginia and Virginia, USA. Abundance estimates are based on $N$-mixture models using geological-topographic and forest structure predictors-only, including the additive effects of state (West Virginia or Virginia), talus or not talus, and canopy cover (\%) for P. punctatus, and state, canopy cover (\%), and vegetation cover (\%) for P. cinereus. Site abundances are separated by burn class (unburned, low-severity [Low], and high-severity [High]). Shapes represent the mean abundance estimate for the following sites: circles for VA not talus, triangles for VA talus, squares for WV not talus, and diamonds for WV talus. Lines represent $95 \%$ confidence intervals. Shading represents a site's canopy cover, with lighter shading represents less canopy cover and darker shading represents more canopy cover.

Figure 3-5. Boxplot summaries of body condition index (BCI) values from our study investigating responses of woodland salamanders to prescribed fire management on Shenandoah Mountain in the George Washington National Forest in West Virginia and Virginia, USA. We found BCI for the Cow Knob Salamander (Plethodon punctatus; $\mathrm{n}=49$; top) was (A) higher on the West Virginia side of the mountain, and (B) some support BCI is higher in unburned areas. For the Eastern Red-Backed Salamander (Plethodon cinereus; $\mathrm{n}=76$; bottom) BCI was (A) lower on the West Virginia side of the mountain and (B) Some support that BCI is higher in unburned areas. 


\section{CHAPTER 1.}

\section{INTRODUCTION}

\section{Amphibian conservation in the Appalachians}

Amphibians are the most imperiled class of vertebrate animals with more than $41 \%$ of the 7,000 species classified as threatened with extinction and an additional $22.5 \%$ considered data deficient by the IUCN (Stuart et al., 2004; Hoffman et al., 2010). Amphibians are facing global declines due to disease, climate change, invasive species and land use changes (Collins and Storfer, 2003; Stuart et al., 2004). In addition to their intrinsic value, amphibians are important ecologically, contribute to ecosystem services, and contain compounds that can be used in medicine (Hocking and Babbitt, 2014).

For salamanders, habitat loss and degradation are the most cited causes of declines (Dodd and Smith, 2003), while climate change is projected to have a major influence on the future distribution of species, resulting in biodiversity loss (Milanovich et al., 2010; Sutton et al. 2015). The Appalachian Mountains of the eastern U.S. are a global biodiversity hotspot for salamanders with high rates of endemism (Kozak et al., 2009; Milanovich et al., 2010). Salamanders are an important component of forest food webs in the Appalachian region because they can be extremely abundant, with up to 10,000 individuals $/ \mathrm{ha}\left(1.0 / \mathrm{m}^{2}\right.$; Petranka et al., 1993). Their biomass often exceeds that of birds, small mammals, and deer (Burton and Likens, 1975; Pauley et al., 2006). Due to their impacts on ecosystem dynamics, they have been proposed as keystone species (Davic and Welsh, 2004). Salamanders perform key ecological functions, such as preying on decomposers that reducing leaf litter decomposition, contributing to carbon sequestration of forests and soil dynamics by burrowing and bringing nutrients to deeper soil levels, and providing an abundant source of energy for predators (Wyman, 1998; Davic and 
Welsh, 2004; Pauley et al., 2006). They have also been found to contribute to diversity of invertebrate communities by significantly reducing abundance and allowing for competitive release (Davic, 1983). Salamanders are considered indicators of forest ecosystem health because they are sensitive to environmental stressors (Welsh and Droege, 2001). Plethodon salamanders are lungless, so they must keep their skin moist to perform cutaneous respiration for gas exchange, making them sensitive to changes in microhabitat characteristics that affect moisture or temperature, such as leaf litter depth, density of coarse woody debris, and canopy cover (Maerz et al., 2009).

\section{The Cow Knob Salamander (Plethodon punctatus)}

\subsection{General biology}

The Cow Knob Salamander (Plethodon punctatus) is a medium-large bodied terrestrial salamander (up to $75 \mathrm{~mm}$ snout-vent length [SVL]) with creamish to whitish spots on its back and sides (Fig. 1). It superficially resembles the slimy salamander (Plethodon glutinosus complex); however, $P$. punctatus can be distinguished from the $P$. glutinosus complex by the presence of 17-18 costal grooves, webbing on their hind feet, and a lightly colored throat (Highton, 1972; Green and Pauley, 1987). Plethodon punctatus was derived from a population of Wehrle's Salamander ( $P$. wehrlei) when it became geographically isolated, likely during a dry period of the Pleistocene epoch (Highton, 1972; 1995). They are a part of the $P$. wehrlei species complex, along with $P$. wehrlei, and the recently recognized Yellow-Spotted Woodland Salamander (P. pauleyi), Blacksburg Salamander (P. jacksoni), and Dixie Cavern Salamander (P. dixi; Kuchta et al., 2018; Felix et al., 2019). 
Surface activity for $P$. punctatus peaks in late spring and early summer and they are also active in the fall; they are less active on the surface in mid-summer, though they can be found when the ground is moist (Fraser, 1976; Flint and Harris, 2005). The diet for P. punctatus consists mostly of ants, beetles, snails, mites, centipedes, and millipedes (Fraser, 1976; Tucker, 1998). The breeding season begins in late August and may continue into the winter (Tucker, 1998). Males become sexually mature in their third year when they are ca. $49 \mathrm{~mm}$ snout-vent length (SVL), while females mature in their fourth year at ca. $59 \mathrm{~mm}$ SVL (Tucker, 1998). Breeding females lay ca. 7 to 16 eggs biennially, and probably lay their eggs around February, below the talus surface (Tucker, 1998).

\subsection{Habitat and conservation}

Plethodon punctatus has a narrow distribution in the Valley and Ridge province of the central Appalachians. The species inhabits forests $>850 \mathrm{~m}$ in elevation on Shenandoah Mountain, North Mountain, and Nathaniel Mountain (Highton, 1972; Graham, 2007), with most populations occurring above $960 \mathrm{~m}$ on the George Washington National Forest (GWNF; Buhlmann et al., 1988). Plethodon punctatus is most abundant on talus slopes with a northern aspect, and individuals typically use rocks as cover objects in and around talus habitat (Buhlmann et al., 1988; Tucker, 1998). There is a greater abundance of P. punctatus on the West Virginia side of Shenandoah Mountain, possibly due to wetter conditions (Buhlmann et al., 1988; Tucker, 1998; Flint and Harris, 2005).

Given their small range and strict habitat requirements, $P$. punctatus is considered a species of special concern by the Virginia Department of Game and Inland Fisheries and the West Virginia Division of Natural Resources. In 1985, the U.S. Fish and Wildlife service 
(USFWS) classified $P$. punctatus as a category 2 species, meaning it might be threatened or endangered, but more information was necessary to make a determination (Buhlmann et al., 1988). Buhlmann et al. (1988) conducted the first study on the conservation status of this species. Abundance was highest for this species on north-facing slopes, with ample rock cover, in hardwood forests where the canopy had not been recently disturbed by logging operations (Buhlmann et al., 1988). The U.S. Forest Service (USFS) established the Shenandoah Mountain Crest - Special Interest Area (SMC-SIA) in 1992, encompassing ca. 17,400 ha of protected land on all federally owned lands above 914 meters on Shenandoah Mountain (Mitchell, 1992). In 1994, the USFS and the USFWS reached an unprecedented conservation agreement between federal agencies, for the USFS to secure and protect this species and its habitat as an alternative to federal listing (Mitchell, 1994). The construction of new roads and commercial timber harvests are not permitted in the conservation area (USFS, 2014). In addition to the SMC-SIA, areas where $P$. punctatus is found below $914 \mathrm{~m}$ in elevation are managed in the same manner (USFS, 2014).

\subsection{Climate change}

Climate change may be the biggest threat to $P$. punctatus due to their limited montane distribution. Previous studies have indicated that $P$. punctatus may lose all of its climatic niche by the year 2050 (Milanovich et al., 2010; Sutton et al., 2015). The vulnerability of $P$. punctatus to climate change was supported by a recent laboratory study (Markle and Kozak, 2018). Out of 16 species of plethodontid salamanders investigated, $P$. punctatus had the lowest capacity for acclimation to warmer temperatures, as well as a low critical thermal maximum. In addition, the metabolic rate of $P$. punctatus was more than 2.5 times greater when exposed to $25^{\circ} \mathrm{C}$ 
temperatures compared to $15^{\circ} \mathrm{C}$ (Markle and Kozak, 2018). This increase in metabolic rate may result in a smaller body size (Caruso et al., 2014). Previous studies on the climatic niche of $P$. punctatus only used a small proportion of the known locations and used coarse climate resolution data (ca. $1 \mathrm{~km}^{2}$ ). A study using all of the known occurrence locations, finer scale climate data, and a species-specific approach is warranted to better understand how climate change might affect $P$. punctatus.

\subsection{Prescribed Fire}

Prescribed fires are used as a forest management tool in occupied P. punctatus habitat on the GWNF to promote and maintain mixed-oak and pine forests, and create open forest conditions (USFS, 2014). Previous investigations on the effects of fire on woodland salamanders found a range of responses that varied among species, geographic region, and fire regime (e.g. Matthews et al., 2010; Ford et al., 2010; O’ Donnell et al., 2015). While the majority of previous studies did not conclude that prescribed fire significantly influenced salamander abundance, moderate declines in abundance were apparent when prescribed fire caused, or was combined with, a decrease in canopy cover (Matthews et al., 2010; Hocking et al., 2013; Mahoney et al., 2015). There have been no studies focused on responses of $P$. punctatus to habitat conditions resulting from prescribed fire. A better understanding of how prescribed fire and forest habitat characteristics affect $P$. punctatus will allow land managers to better manage habitat for this species. 


\section{Research goals and summary of chapters}

The goal of this research is to quantify the influence of broad and fine-scale habitat characteristics, and assess the influence of climate change and active habitat management using prescribed fire, on the distribution and abundance of $P$. punctatus. In Chapter 2, I assessed the effects of geological and climatic variables on habitat suitability for this species, and projected how climate change may impact habitat suitability in the future. In Chapter 3, I assessed the effects of prescribed fire and forest characteristics on the abundance of this species as well as sympatric populations of the common and widely distributed Eastern Red-Backed Salamander (Plethodon cinereus). The results of this research will provide the USFS and other management agencies with important species and habitat information that can be used to support conservation efforts for P. punctatus.

\section{References}

Buhlmann, K.A., Pague, C.A., Mitchell J.C., Glasgow R.B., 1988. Forestry operations and terrestrial salamanders: techniques in a study of the Cow Knob Salamander, Plethodon punctatus. Pages 38-44 in Management of amphibians, reptiles, and small mammals in North America. R.C. Szaro, K.E. Severson, D.R. Patton, technical coordinators. U.S. Forest Service General Technical Report RM-166, Fort Collins, Colorado, USA.

Burton, T.M., Likens, G.E., 1975. Salamander populations and biomass in the Hubbard Brook Experimental Forest, New Hampshire. Copeia 1975:541-546.

Collins, J.P.A., Storfer, A., 2003. Global amphibian declines: sorting the hypotheses. Divers. Distrib. 9:89-98. 
Davic, R.D., Welsh Jr., H.H., 2004. On the ecological roles of salamanders. Annu. Rev. Ecol. Syst. 35:405-435.

Davic, R.D., 1983. An investigation of salamander guild predation in a North Carolina stream: an experimental approach. PhD thesis. Kent State University, Ohio, USA.

Dodd Jr., C.K., Smith, L.L., 2003. Habitat destruction and alteration: historical trends and future prospects for amphibians. Pages 94-112 in Amphibian Conservation. R.D. Semlitsch, editor. 2003. Washington, DC: Smithson. Inst.

Dodd Jr., C.K., Dorazio. R.M., 2004. Using counts to simultaneously estimate abundance and detection probabilities in salamander communities. Herpetologica 60:468-478.

Felix, Z.I., Wooten, J.A., Pierson, T.W., Camp, C.D., 2019. Re-evaluation of the Wehrle's salamander (Plethodon wehrlei Fowler and Dunn) species group (Caudata: Plethodontidae) using genomic data, with the description of a new species. Zootaxa 4609:429-448.

Flint, W.D. 2004. Ecology and conservation of the Cow Knob salamander, Plethodon punctatus. Thesis, James Madison University, Harrisonburg, USA.

Flint, W.D., Harris, R.N., 2005. The efficacy of visual encounter surveys for population monitoring of Plethodon punctatus (Caudata: Plethodontidae). J. Herpetol. 39:578-584.

Ford, W.M., Rodrigue, J.L., Rowan, E.L., Castleberry, S.B., Schuler, T.M., 2010. Woodland salamander response to two prescribed fires in the central Appalachians. Forest Ecol. Manag. 260:1003-1009.

Fraser, D.F., 1976. Coexistence of salamanders in the genus Plethodon: a variation of the Santa Rosalia theme. Ecology 57:238-251. 
Graham, M.R., 2007. Distribution and conservation genetics of the Cow Knob salamander, Plethodon punctatus Highton (Caudata: Plethodontidae). Thesis, Marshall University, Huntington, USA.

Gifford, M.E., Kozak, K.H., 2012. Islands in the sky or squeezed at the top? Ecological causes of elevational range limits in montane salamanders. Ecography 35:193-203.

Grant, E.H.C., Brand, A.B., De Wekker, S.F., Lee, T.R., Wofford, J.E., 2018. Evidence that climate sets the lower elevation range limit in a high-elevation endemic salamander. Ecol. Evol. 8:7553-7562.

Green, N.B., Pauley. T.K., 1987. Amphibians and Reptiles in West Virginia. University of Pittsburgh Press, Pittsburgh, Pennsylvania, USA.

Harper, C.A., Ford, W.M., Lashley, M.A., Moorman, C.E., Stambaugh, M.C., 2016. Fire effects on wildlife in the Central Hardwoods and Appalachian regions, USA. Fire Ecol. 12:127159.

Highton, R., 1972. Distributional interactions among eastern North American salamanders of the genus Plethodon. Virginia Polytechnic Institute and State University Research Division Monograph 4:139-188.

Highton, R., 1995. Speciation in eastern North American salamanders of the genus Plethodon. Annu. Rev. Ecol. Syst. 26:579-600.

Hocking, D.J., Babbitt. K.J., 2014. Amphibian contributions to ecosystem services. Herpetol. Conserv. Bio. 9:1-17.

Hocking, D.J., Connette, G.M., Conner, C.A., Scheffers, B.R., Pittman, S.E., Peterman, W.E., Semlitsch, R.D., 2013. Effects of experimental forest management on a terrestrial, woodland salamander in Missouri. Forest Ecol. Manag. 287:32-39. 
Hoffmann, M., Hilton-Taylor, C., Angulo, A., Böhm, M., Brooks, T.M., Butchart, S.H.M., Carpenter, K.E., Chanson, J., Collen, B., Cox, N.A., et al., 2010. The impact of conservation on the status of the world's vertebrates. Science 330:1503-1509.

Kozak, K.H., Wiens, J.J., 2010. Niche conservatism drives elevational diversity patterns in Appalachian salamanders. Am. Nat. 176:40-54.

Kuchta, S.R., Brown, A.D., Highton, R., 2018. Disintegrating over space and time: paraphyly and species delimitation in the Wehrle's Salamander complex. Zool. Scrip. 47:285-299.

Maerz, J.C., Nuzzo, V.A., Blossey, B., 2009. Declines in woodland salamander abundance associated with non-native earthworm and plant invasions. Conserv. Biol. 23:975-981. Mahoney, K.R., Russell, K.R., Ford, W.M., Rodrigue, J.L., Riddle, J.D., Schuler, T.M., Adams, M.B., 2016. Woodland salamander responses to a shelterwood harvest-prescribed burn silvicultural treatment within Appalachian mixed-oak forests. Forest Ecol. Manag. 359:277-285.

Markle, T.M., Kozak, K.H., 2018. Low acclimation capacity of narrow-ranging thermal specialists exposes susceptibility to global climate change. Ecol. Evol. 8:4644-4656.

Matthews, C.E., Moorman C.E., Greenberg C.H., Waldrop, T.A., 2010. Response of reptiles and amphibians to repeated fuel reduction treatments. J. Wildlife Manage. 74:1301-1310.

Milanovich, J.R., Peterman, W.E., Nibbelink, N.P., Maerz, J.C., 2010. Projected loss of a salamander diversity hotspot as a consequence of projected global climate change. PLoS ONE 5:e12189.

Mitchell, J.C., 1992. Prelisting conservation plan for the Cow Knob Salamander (Plethodon punctatus) in the George Washington National Forest. Report submitted to the USDA Forest Service. 
Mitchell, J.C., 1994. Conservation agreement for the Cow Knob Salamander. Report submitted to the USDA Forest Service.

O’Donnell, K.M., Thompson F.R., Semlitsch R.D., 2015. Prescribed fire and timber harvest effects on terrestrial salamander abundance, detectability and microhabitat use. J. Wildlife Manage. 79:766-775.

Pauley, T.K., Watson, M.B., Kochenderfer, J.N., Little, M., 2006. Response of salamanders to experimental acidification treatments. Pages 189-206 in The Fernow Watershed acidification study. M. B. Adams, D. R. DeWalle, and J. L. Hom, editors. Springer, Dordrecht, Netherlands.

Petranka, J.W., Eldridge, M.E., Haley. K.E., 1993. Effects of timber harvesting on southern Appalachian salamanders. Conserv. Biol. 7:363-370.

Stuart, S.N., Chanson, J.S., Cox, N.A., Young, B.E., Rodrigues, A.S.L., Fischmann, D.L., Waller. R.W., 2004. Status and trends of amphibian declines and extinctions worldwide. Science 306:1783-1786.

Sutton, W.B., Barrett, K., Moody, A.T., Loftin, C.S., deMaynadier, P.G., Nanjappa, P., 2015. Predicted changes in climatic niche and climate refugia of conservation priority salamander species in the northeastern United States. Forests 6:1-26.

Tucker, R.B., 1998. Ecology and natural history of the Cow Knob Salamander, Plethodon punctatus Highton, in West Virginia. Thesis, Marshall University, Huntington, USA.

U.S. Forest Service. 2014. Revised land and resource management plan George Washington National Forest. Management Bull. R8-MB 143A. Roanoke, VA: U.S. Department of Agriculture, Forest Service, Region 8, George Washington National Forest. 374 p. 
Wyman, R.L., 1998. Experimental assessment of salamanders as predators of detrital food webs: effects on invertebrates, decomposition and the carbon cycle. Biodivers. Conserv. 7:641650.

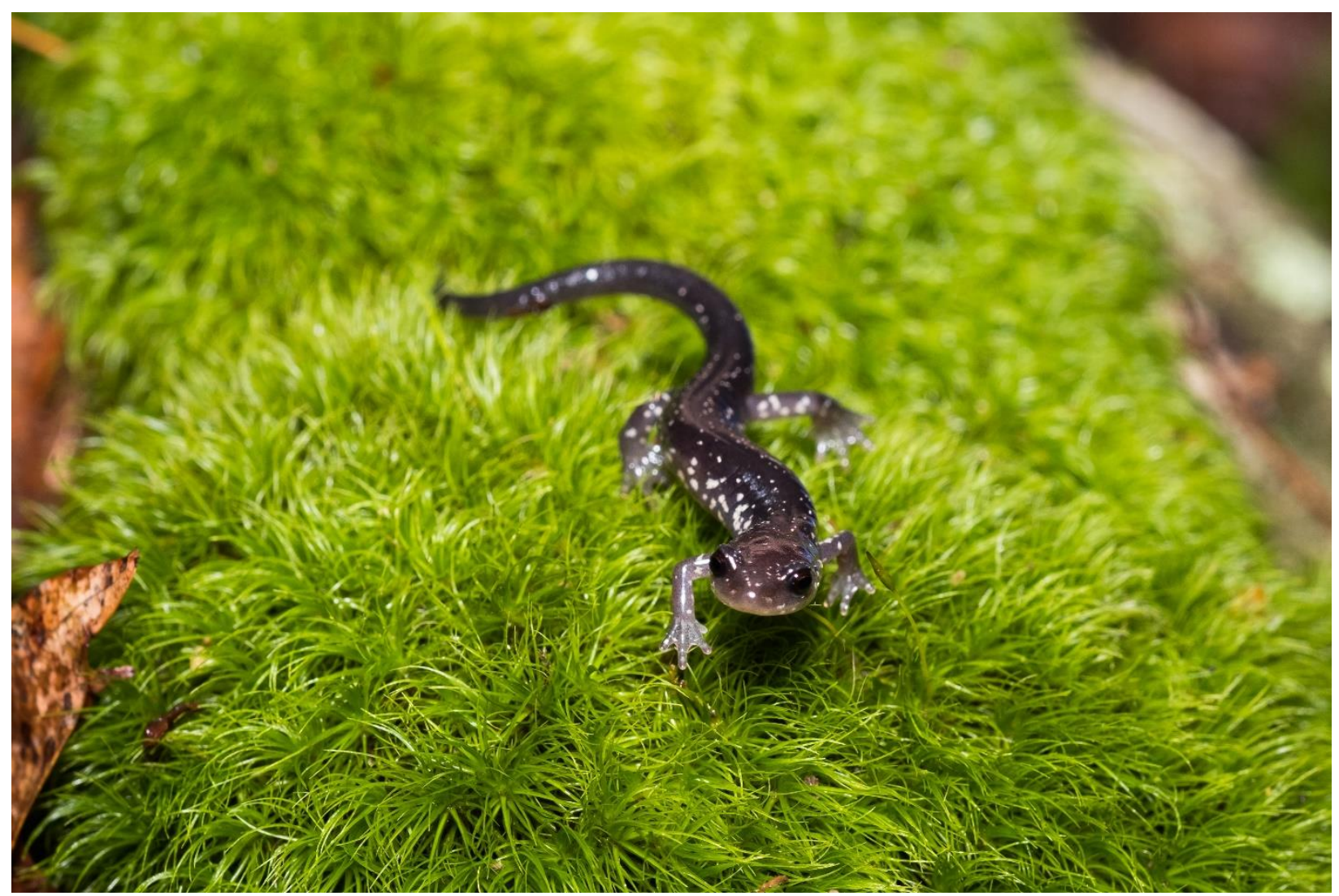

Fig. 1. An adult Cow Knob Salamander (Plethodon punctatus) in moss-covered talus habitat. Plethodon punctatus superficially resembles Slimy Salamanders (Plethodon glutinosus complex), but the species has more webbing between the toes and a lighter colored throat. Photograph used with permission from D.J. Brown. 


\title{
Chapter 2.
}

\section{VULNERABILITY OF HIGH-ELEVATION SALAMANDERS TO CLIMATE CHANGE: A CASE STUDY WITH THE COW KNOB SALAMANDER (PLETHODON PUNCTATUS)}

\begin{abstract}
Woodland salamanders (genus Plethodon) are mid-level predators that play a fundamental role in the food web of Appalachian forests. Rapid contemporary climate change is a potential threat to long-term persistence of high-elevation, isolated, endemic species because they are thermal specialists that depend on the availability of their unique climatic niche. However, little is known about habitat selection for many of the narrowly-distributed species and how microrefugia may help mitigate the effects of climate warming. The Cow Knob Salamander (Plethodon punctatus) is a species of conservation concern found at high elevations in the Valley and Ridge Province of western Virginia and eastern West Virginia. We used habitat suitability models to examine relationships between landscape characteristics, climate variables, and $P$. punctatus occurrence, and estimated effects of future climate scenarios on the species' climatic niche. We found that elevation, slope, aspect, and hillshade were influential landscape predictors of species occurrence, and that mean annual temperature was the most influential climate variable. Future climate projections indicated this species will likely lose most of its climatic niche by mid-century, and that amount of suitable habitat will continue to decline through 2100 . However, we also identified several pockets of habitat that may represent climate change refugia for $P$. punctatus. Our study provides quantitative estimates that support the general concern that high-elevation endemic salamanders are particularly vulnerable to climate change. Our models
\end{abstract}


can be used by natural resource managers to guide current $P$. punctatus monitoring and habitat conservation efforts, as well as to identify focal areas that will likely serve as refugia for the species as the climate continues to change over this century.

\section{Introduction}

The Appalachian Mountain region in the eastern United States is a global biodiversity hotspot for salamanders (Milanovich et al., 2010; Rissler and Smith, 2010), with many highelevation endemic woodland salamanders (genus Plethodon) of conservation concern, such as the Shenandoah Salamander (P. shenandoah), Cheat Mountain Salamander (P. nettingi), Peaks of Otter Salamander (P. hubrichti), Weller's Salamander (P. welleri), and Cow Knob Salamander ( $P$. punctatus). There is broad concern that these salamanders are particularly vulnerable to climate change because of the inability to expand to higher elevations or latitudes as the climate warms (Milanovich et al., 2010). Further, there is concern about the potential for increasing interspecific competition as high elevations become more suitable for other salamander species (Kroschel et al., 2014; Milanovich et al., 2010; Moskwik, 2014).

Habitat selection by wildlife occurs at multiple scales, ranging from individual-level resource acquisition to the geographic distribution of a species (Johnson, 1980). Important habitat characteristics are spatially and temporally dynamic, and the importance of a given variable is dependent on the scale of inference (Mayor et al., 2009). While there are many biotic and abiotic factors that affect local-scale distributions of woodland salamander species, landscape-scale distributions are largely driven by climatic conditions (Kozak and Wiens, 2010). These species are lungless ectotherms that are dependent on both temperature and moisture for cutaneous respiration and activity patterns (Feder, 1983). In particular, climate constraints on 
physiology set the lower elevation limits for many montane salamander species (Gifford and Kozak, 2012; Grant et al., 2018). Narrowly-distributed species are often specialists for their unique ecological niches and will have less plasticity in their response to climate change than more widely-distributed species (Markle and Kozak, 2018). For example, Grant et al. (2018) found the abrupt range limit observed in $P$. shenandoah is likely due to whether a site is above the cloud base height (i.e., the lower elevation at which clouds form). Estimating the vulnerability of high-elevation endemic salamanders to rapid contemporary climate change is critical for guiding climate change adaptations strategies by natural resource managers (Dawson et al., 2011; Bierbaum et al., 2013; Fischman et al., 2014).

Most of the research on habitat use and quality for woodland salamanders has focused on site-level characteristics, such as species density in relation to forest structure (Hocking et al., 2013; Homyack and Haas, 2009; Pough et al., 1987). However, as computing power and availability of fine-grained, broad-scale spatial data have increased, researchers have begun to focus on identifying and quantifying the influence of landscape-level habitat characteristics on woodland salamander occurrence (e.g., Dillard et al., 2008; Keyser et al., 2011; Suzuki et al., 2008). Further, several studies have projected changes in distributions of woodland salamanders based on predicted environmental changes, particularly climate change (Milanovich et al., 2010; Parra-olea et al., 2005; Sutton et al., 2015). These models can contribute to proactive conservation efforts in the face of climate change through spatially-explicit quantification of species vulnerability (Bagne et al., 2014; Dawson et al., 2011).

One woodland salamander that is potentially highly vulnerable to rapid contemporary climate change is $P$. punctatus, a high-elevation species that is endemic to a small region (ca. $720 \mathrm{~km}^{2}$ ) along the eastern and western border of West Virginia and Virginia, respectively. The 
majority of historically known-occupied locations are on Shenandoah Mountain in the George Washington National Forest, which occurs in the Valley and Ridge Province, the driest region in the central Appalachians (Lafon and Grissino-Mayer, 2007). The comparatively dry climate may limit the local distribution of the species, relegating it to the limited areas with cool, moist conditions (Flint and Harris, 2005). For example, Buhlmann et al., (1988) documented greater relative abundance of $P$. punctatus on north-facing slopes and at high elevations, presumably due to cooler and wetter conditions in these areas.

Two previous studies indicated that $P$. punctatus may be extremely vulnerable to climate change, as $100 \%$ of their climatic niche was projected to disappear by mid-century in both studies (Milanovich et al., 2010; Sutton et al., 2015). However, both were community-level studies, and thus did not explicitly focus on delineating the variables most influential for the occurrence of $P$. punctatus. Further, both studies used a small proportion of the known occurrence points for $P$. punctatus to train the models, and somewhat coarse-grained climate data (ca. $\left.1 \mathrm{~km}^{2}\right)$. Given the potential for this species to be among the most vulnerable woodland salamanders to climate change, a more robust and refined assessment of its vulnerability is warranted.

The purposes of this study were to 1) delineate important landscape-scale predictors of $P$. punctatus occurrence, 2) estimate fine-scale probability of occurrence under contemporary environmental conditions across the species' distribution, and 3) project fine-scale probability of occurrence under predicted future environmental conditions. Results of this study can be used to enhance management of $P$. punctatus by guiding current monitoring and habitat conservation efforts, as well as identifying focal areas that will likely serve as refugia for the species as the climate changes. 


\section{Methods}

\subsection{Species occurrence data and study area}

We compiled all known $P$. punctatus locations ( $\mathrm{n}=229$, precise locations withheld due to conservation concerns) from federal and university researchers who have conducted surveys over the past three decades. We bounded our study area based on the distribution of the species and dispersal boundaries. First, we created a buffer of $30 \mathrm{~km}$ around observed locations on the periphery of the distribution to incorporate potentially occupied habitat that has not been surveyed. We then restricted the lower elevation study boundary to $500 \mathrm{~m}$; all observed locations are above $625 \mathrm{~m}$. Lastly, because this species has never been found west of Cowpasture River and the South Fork of the South Branch Potomac River, or east of the Shenandoah Valley, we considered these to be dispersal barriers and restricted our study area to these barriers. It is unlikely that $P$. punctatus can disperse from the defined study area because unsuitable, low elevation habitat surrounds the mountains, and plethodontid salamanders have limited longdistance dispersal capabilities (Gibbs, 1998). We gridded the study area into $24 \mathrm{~m}^{2}$ cells (i.e., the resolution of the digital elevation model [DEM] we used), and used the observed locations to define known occurrence cells. We used the remaining cells to generate background habitat data.

\subsection{Modeling overview}

We used a habitat suitability model (HSM) approach to estimate relationships between environmental variables and species occurrence (Boyce et al., 1999; Guisan and Zimmermann, 2000). HSMs estimate spatially-explicit habitat quality based on correlations between species occurrence and environmental variables (Hirzel and Le Lay, 2008; Phillips et al., 2006). For this study, we created two HSMs to address our study objectives. First, we created a landscape 
model, with the goal of maximizing accuracy for the contemporary spatially-explicit probability of occurrence of $P$. punctatus. Second, we created a climatic niche model, with the goal of estimating how climate change will influence the distribution of this species.

We used the MaxLike HSM for this study (Royle et al., 2012). MaxLike uses species occurrence data coupled with background environmental data to model species-environment relationships. The function is a generalized linear model with a Bernoulli distribution and parameter value estimation using maximum likelihood (Royle et al., 2012). Although we acknowledge that presence-absence models are generally preferable to presence-only models (Brotons et al., 2004; Yackulic et al., 2013), a robust absence data set is not currently available for this species. In addition, false absences in species monitoring data can be prevalent when detection probability is low (Hirzel et al., 2002), as is the case for P. punctatus (Flint and Harris, 2005), potentially resulting in biased estimates from presence-absence models (Gu and Swihart, 2004; MacKenzie, 2006). We chose MaxLike over other presence-only models such as MaxEnt because previous research found that MaxLike tended to perform similarly (Merow and Silander, 2014), or better (Fitzpatrick et al., 2013). We created HSMs using the package 'maxlike' (version 0.1 .7 ) in the statistical software $\mathrm{R}$ (version 3.5.1). We used the cloglog link function, rather than the default logit link function, because it resulted in a better model fit.

\subsection{Landscape variables}

We obtained a 1 arc second (ca. $24 \mathrm{~m}^{2}$ at $39^{\circ}$ North) resolution DEM through the USGS National Elevation Dataset. From this layer, we derived slope, heat load index (HLI), topographical position index (TPI), and hillshade using ArcGIS (version 10.4). We standardized all variables by subtracting the mean and dividing by the standard deviation. HLI is a 
measurement of the potential heat and incident radiation a site receives due to aspect and slope (McCune and Keon, 2002). This index assigns higher values for locations with a southwest aspect because they receive higher maximum temperatures from the afternoon sun. The following equation rescales aspect to a scale from 0 for cooler northeast-facing slopes, to 1 for warmer southwest-facing slopes:

$$
\text { Heat Load Index }=\frac{1-\cos (\theta-45)}{2}
$$

where $\theta=$ aspect in degrees east of north. We calculated TPI as the slope position relative to the surrounding $600 \mathrm{~m}$, with negative values representing areas that are lower than the surrounding area (i.e., valleys and ravines), and positive values represent areas that are higher than the surrounding area (i.e., ridges).

\subsection{Climate variables}

For contemporary climate normals, we used 30-year averages (1980-2010) of estimated monthly precipitation and temperature that were statistically downscaled to $550 \mathrm{~m}^{2}$ resolution by CLIMsystems Ltd (Hamilton, New Zealand). We resampled the layers to the resolution of the landscape variables. We initially examined the 19 bioclimatic variables from WorldClim (Himjans et al. 2005; Table 1), because they are widely used in climatic niche modeling. For highly correlated climatic variables $\left(\mathrm{r}^{2}>0.75\right)$, we retained the variables that were most biologically relevant based on woodland salamander ecology (Rissler et al., 2006). Our final analyses included 4 climatic variables, mean annual temperature, precipitation in the warmest quarter (i.e., June to August), precipitation in the wettest quarter (i.e., April to June), and temperature seasonality (i.e., the standard deviation in monthly temperature $x 100$ ). In addition to the climate variables, we included two topographical variables, HLI, and hillshade, in our 
climatic niche models. Topographic variables that influence microclimate are often overlooked in climatic nice modeling (Title and Bemmles, 2018), and ignoring them may lead to an overestimation of extinction risk (Lembrechts et al., 2018).

The IPCC recommends using an ensemble of GCMs to account for variability in climate model projections and to buffer against unusually high or low projections from single models (IPCC 2010). We extracted the median as well as the $10^{\text {th }}$ and $90^{\text {th }}$ percentile temperature scenarios from an ensemble of 31 global climate models using the 4.5 and 8.5 representative concentration pathways (RCPs) for the years 2050 and 2100. Each RCP represents a different greenhouse gas scenario. The RCP4.5 scenario represents a pathway where global greenhouse emissions gradually increase, followed by a decline after 2030. The RCP8.5 scenario represents a 'baseline' scenario pathway with no climate mitigation target and an increase in emissions throughout the century (Moss et al., 2010).

\subsection{Model selection}

We fit models using a forward stepwise approach based on Akaike's Information Criterion corrected for small sample size $\left(\mathrm{AIC}_{c}\right)$. Models with a lower score were ranked as more parsimonious. We calculated Akaike weights $\left(\mathrm{w}_{i}\right)$ to determine the weight of evidence for each model (Anderson and Burnham, 2002). For the best approximating landscape and climatic niche model, we performed model validation using the 'sdm' package (version 1.0-46) in program R. We ran 10 iterations of 10-fold cross-validation and considered models that had an area under the receiver operating characteristic curve (AUC) of 0.7-0.9 to be informative, and models with an AUC > 0.9 to be "very good" (Baldwin, 2009; Sutton et al., 2015). 


\subsection{Suitability thresholds}

We used a threshold approach to create three probability of occurrence categories: not suitable, low occurrence probability, and high occurrence probability. Values above the ten fixed cumulative value (i.e., the value that results in $10 \%$ omission of training data) were considered to have a high occurrence probability. Low occurrence probability was determined by the minimum training presence threshold, where all known locations were correctly predicted by the model. Probability scores lower than the minimum training presence threshold were considered not suitable. The minimum training presence and $10 \%$ omission thresholds can be considered liberal and conservative approaches, respectively (Sutton et al., 2015).

\section{Results}

\subsection{Landscape model}

Out of the 19 models fit, the elevation/HLI/hillshade/slope model was the best approximating model (Table 2). Plethodon punctatus occurrence was positively associated with elevation, slope, and hillshade, and negatively associated with HLI (Table 3). This model resulted in $40.9 \%$ not suitable, $42.1 \%$ low probability of occurrence, and $17.0 \%$ high probability of occurrence habitat within the study area. Most of the high probability of occurrence habitat was located on the ridgeline of Shenandoah Mountain (Fig. 1). This model received an AUC of 0.936 (+/- 0.017 SD). The second-best model, elevation/HLI/slope/hillshade/TPI, also received empirical support (Table 2). However, it is very similar to the top model, and TPI was not significantly correlated with $P$. punctatus presence.

\subsection{Climate niche model}


The best approximating climate niche model was the mean annual temperature/HLI/hillshade model (Table 2). Plethodon punctatus occurrence was positively associated with hillshade and negatively associated with HLI and mean annual temperature. Similar to the landscape model, most of the high probability of occurrence habitat was located on the ridgeline of Shenandoah Mountain. However, this model had a larger area of projected high probability of occurrence (Fig. 1). This model received an AUC score of 0.906 (+/- 0.028 SD). No other climate niche model received strong empirical support.

Median projected increases in temperature for the study area ranged from $1.56{ }^{\circ} \mathrm{C}(2050$, $\mathrm{RCP} 4.5)$ to $5.14{ }^{\circ} \mathrm{C}(2100, \mathrm{RCP} 8.5$; Table 4). Both projected increases in temperature resulted in a drastic reduction of suitable habitat for $P$. punctatus. The models projected $76-100 \%$ loss of high occurrence probability habitat and $31-100 \%$ loss of low occurrence probability habitat by 2050 (Table 4). The models projected an $85-100 \%$ loss in high occurrence probability habitat and $50-100 \%$ loss in low occurrence probability habitat by the year 2100 (Table 4). However, the models identified potential climate refugia in areas that are high elevation, receive little direct solar radiation (i.e. low HLI and high hillshade), and near the ridgeline of Shenandoah Mountain (Fig. 2).

\section{Discussion}

Our landscape HSM indicated that $P$. punctatus have limited suitable habitat under contemporary climate conditions, mostly at high elevations near the ridgeline of Shenandoah Mountain. While previous studies observed that $P$. punctatus occupancy and abundance was greater at higher elevations (i.e., Buhlmann et al., 1988; Downer, 2008), our research is the first to explicitly model the relationship between elevation and occurrence across the species' 
distribution. This model shows that $P$. punctatus are mostly relegated to areas with cool, moist conditions (i.e., high elevations and areas with little solar radiation).

The results of our climatic niche projections are consistent with the two previous studies (Milanovich et al., 2010; Sutton et al., 2015), and suggest that the P. punctatus will lose most its climatic niche, and therefore suitable habitat, by the year 2050, with further declines by the year 2100. However, the previous climatic niche studies showed a $100 \%$ loss in suitable habitat by 2050, whereas our study indicates there will likely be areas of climate refugia. Specifically, our climate niche model indicates that high elevation areas with a low HLI and high hill shade (i.e., areas that receive less solar radiation) will be important refugia as the climate warms. Thus, our study supports the importance of incorporating microrefugia in habitat suitability models (Lembrechts et al., 2018).

Although our study indicates high vulnerability of $P$. punctatus populations to climate change across their distribution, we acknowledge that species occurrence-environment correlations under contemporary conditions may not extrapolate well to future novel environmental conditions (Gustafson, 2013). However, the vulnerability of $P$. punctatus to increasing temperature is supported by a recent laboratory study that investigated thermal acclimation ability and tolerance of plethodontid salamanders (Markle and Kozak, 2018). For the 16 species investigated, $P$. punctatus had the lowest capacity for acclimation to warmer temperatures, as well as a low critical thermal maximum. In addition, the metabolic rate of $P$. punctatus was more than 2.5 times greater when exposed to $25^{\circ} \mathrm{C}$ temperatures compared to 15 ${ }^{\circ} \mathrm{C}$ (Markle and Kozak, 2018). Thus, the mechanism underlying the apparent strong influence of mean annual temperature on habitat suitability could be related to temperature being a limiting factor for surface activity, or related to the influence of temperature on baseline energy 
expenditure. Specifically, $P$. punctatus spend the majority of time occupying deep subterranean talus habitat, which generally reflects mean annual temperature conditions (Mammola and Leroy, 2018).

The landscape model we developed for this study is currently the most robust HSM for $P$. punctatus, and our model validation indicated it has high predictive accuracy. However, we were not able to find a variable that correlated strongly with the presence of talus habitat, which is positively correlated with local $P$. punctatus occupancy (Buhlmann et al., 1988), and we encourage future development of this habitat variable to improve model accuracy. A potential limitation of correlative climate niche models is they do not account for potential evolutionary responses to climate change (Luoto et al., 2005). However, temperatures are projected to warm at a much faster rate than previous climate adaptation rates for terrestrial vertebrates (Deutsch et al., 2008; Quintero and Wiens, 2013). Additionally, we emphasize that our climate niche models project a loss of suitable habitat, not species extirpation. It is likely that $P$. punctatus will temporarily persist beyond the point when their habitat is no longer able to support stable population growth rates at dynamic equilibrium, referred to as extinction debt (Dullinger et al., 2012; Kuussaari et al., 2009).

In summary, our study supports the general concern that high-elevation endemic salamanders in the Appalachian region are particularly vulnerable to climate change, and provides useful information to enhance conservation of the P. punctatus, a species of conservation concern. Our landscape model can be used by natural resource managers to guide current $P$. punctatus habitat conservation efforts, as well as to direct future survey efforts that could facilitate the discovery of new $P$. punctatus populations, thus expanding our knowledge of the range-wide distribution of the species. Our climate niche models identify potential areas of 
refugia under warmer climate conditions, thus providing natural resource managers with defined areas to focus habitat and climate adaptation management efforts.

\section{Acknowledgments}

We thank all of the individuals who have contributed knowledge and data on the ecology and distribution of Plethodon punctatus, particularly W. Flint, R. Highton, D. Fraser, and R. Tucker. We thank C. Rota and M. Strager for modeling assistance. We acknowledge the World Climate Research Programme's Working Group on Coupled Modelling, which is responsible for CMIP, and we thank the climate modeling groups for producing and making available their model output.

\section{Literature Cited}

Anderson, D.R., Burnham, K.P., 2002. Avoiding pitfalls when using information-theoretic methods. J. Wildlife Manage. 66:912-918.

Bagne, K.E., Friggens, M.M., Coe, S.J., Finch, D.M., 2014. The importance of assessing climate change vulnerability to address species conservation. J. Fish Wildl. Manag. 5, 450-462.

Baldwin, R.A., 2009. Use of maximum entropy modeling in wildlife research. Entropy 11:854866.

Bierbaum, R., Smith, J.B., Lee, A., Blair, M., Carter, L., Chapin, F.S., Fleming, P., Ruffo, S., Stults, M., McNeeley, S., Wasley, E., 2013. A comprehensive review of climate adaptation in the United States: more than before, but less than needed. Mitig. Adapt. Strat. Gl. 18:361-406. 
Boyce, M.S., McDonald, L.L., 1999. Relating populations to habitats using resource selection functions. Trends Ecol. Evol. 14:268-272.

Brotons, L., Thuiller, W., Araújo, M.B., Hirzel, A.H., 2004. Presence-absence versus presenceonly modelling methods for predicting bird habitat suitability. Ecography 27:437-448.

Buhlmann, K.A., Pague, C.A., Mitchell J.C., Glasgow R.B., 1988. Forestry operations and terrestrial salamanders: techniques in a study of the Cow Knob Salamander, Plethodon punctatus. Pages 38-44 in Management of amphibians, reptiles, and small mammals in North America. R.C. Szaro, K.E. Severson, D.R. Patton, technical coordinators. U.S. Forest Service General Technical Report RM-166, Fort Collins, CO, USA.

Dawson, T.P., Jackson, S.T., House, J.I., Prentice, I.C., Mace, G.M., 2011. Beyond predictions: biodiversity conservation in a changing climate. Science 332:53-58.

Deutsch, C.A., Tewksbury, J.J., Huey, R.B., Sheldon, K.S., Ghalambor, C.K., Haak, D.C., Martin, P.R., 2008. Impacts of climate warming on terrestrial ectotherms across latitude. P. Natl. Acad. Sci. USA 105:6668-6672.

Dillard, L.O., Russell, K.R., Ford, M.W., 2008. Macrohabitat models of occurrence for the threatened Cheat Mountain Salamander, Plethodon nettingi. Appl. Herpetol. 5:201-224.

Downer, H.R., 2009. Distribution of woodland salamanders of the valley and ridge in West Virginia. Thesis, Marshall University, Huntington, VA, USA.

Dullinger, S., Gattringer, A., Thuiller, W., Moser, D., Zimmermann, N.E., Guisan, A., Willner, W., Plutzar, C., Leitner, M., Mang, T., Caccianiga, M., 2012. Extinction debt of highmountain plants under twenty-first-century climate change. Nat. Clim. Change 2:619-622.

Feder, M.E., 1983. Integrating the ecology and physiology of plethodontid salamanders. Herpetologica 39:291-310. 
Fischman, R.L., Meretsky, V.J., Babko, A., Kennedy, M., Liu, L., Robinson, M., Wambugu, S., 2014. Planning for adaptation to climate change: Lessons from the US National Wildlife Refuge System. BioScience 64:993-1005.

Fitzpatrick, M.C., Gotelli, N.J., Ellison, A., 2013. MaxEnt vs. MaxLike: Empirical comparisons with ant species distributions. Ecosphere 4:1-15.

Flint, W.D., Harris, R.N., 2005. The efficacy of visual encounter surveys for population monitoring of Plethodon punctatus (Caudata: Plethodontidae). J. Herpetol. 39:578-584.

Gibbs, J.P. 1998. Distribution of woodland amphibians along a forest fragmentation gradient. Landscape Ecol. 13:263-269.

Gifford, M.E., Kozak, K.H., 2012. Islands in the sky or squeezed at the top? Ecological causes of elevational range limits in montane salamanders. Ecography 35:193-203.

Grant, E.H.C., Brand, A.B., De Wekker, S.F., Lee, T.R., Wofford, J.E., 2018. Evidence that climate sets the lower elevation range limit in a high-elevation endemic salamander. Ecol. Evol. 8:7553-7562.

Gu, W., Swihart, R.K., 2004. Absent or undetected? Effects of non-detection of species occurrence on wildlife-habitat models. Biol. Conserv. 116:195-203.

Guisan, A., Zimmermann, N.E., 2000. Predictive habitat distribution models in ecology. Ecol. Model. 135:147-186.

Gustafson, E.J., 2013. When relationships estimated in the past cannot be used to predict the future: using mechanistic models to predict landscape ecological dynamics in a changing world. Landscape Ecol. 28:1429-1437.

Hijmans, R.J., Cameron, S.E., Parra, J.L., Jones, P.G., Jarvis, A., 2005. Very high resolution interpolated climate surfaces for global land areas. Int. J. Climatol. 25:1965-1978. 
Hirzel, A.H., Hausser, J., Chessel, D., Perrin, N., 2002. Ecological-niche factor analysis: How to compute habitat-suitability maps without absence data? Ecology 83:2027-2036.

Hirzel, A.H., Le Lay, G., 2008. Habitat suitability modelling and niche theory. J. Appl. Ecol. 45:1372-1381.

Hocking, D.J., Babbitt, K.J., Yamasaki, M., 2013. Comparison of silvicultural and natural disturbance effects on terrestrial salamanders in northern hardwood forests. Biol. Conserv. 167:194-202.

Homyack, J.A., Haas, C.A., 2009. Long-term effects of experimental forest harvesting on abundance and reproductive demography of terrestrial salamanders. Biol. Conserv. 142:110-121.

Intergovernmental Panel on Climate Change (IPCC). 2010. Good-practice guidance-paper on assessing and combining multi-model climate projections. IPCC Expert Meeting on Assessing and Combining Multi-Model Climate Projections, 25-27 January 2010. Boulder, CO, USA. 13 pp.

Johnson, D.H., 1980. The comparison of usage and availability measurements for evaluating resource preference. Ecology 61:65-71.

Keyser, P.D., Williams, L.A., Kelly, K.M., Haas, C.A., Ford, V.L., Wigley, T.B., 2011. An assessment of distribution patterns of terrestrial salamanders in the central Appalachians using two landscape models. Am. Midl. Nat. 166:194-210.

Kozak, K.H., Wiens, J.J., 2010. Niche conservatism drives elevational diversity patterns in Appalachian salamanders. Am. Nat. 176:40-54. 
Kroschel, W.A., Sutton, W.B., McClure, C.J.W., Pauley, T.K., 2014. Decline of the Cheat Mountain Salamander over a 32-year period and the potential influence of competition from a sympatric species. J. Herpetol. 48:415-422.

Kuussaari, M., Bommarco, R., Heikkinen, R.K., Helm, A., Krauss, J., Lindborg, R., Öckinger, E., Pärtel, M., Pino, J., Rodà, F., Stefanescu, C., Teder, T., Zobel, M., Steffan-Dewenter, I., 2009. Extinction debt: a challenge for biodiversity conservation. Trends Ecol. Evol. 24:564-571.

Lafon, C.W., Grissino-Mayer, H.D., 2007. Spatial patterns of fire occurrence in the central Appalachian Mountains and implications for wildlife fire management. Phys. Geogr. 28:120.

Lembrechts, J.J., Nijs, I., Lenoir, J., 2018. Incorporating microclimate into species distribution models. Ecography 42:1-13.

Luoto, M., Pöyry, J., Heikkinen, R.K., Saarinen, K., 2005. Uncertainty of bioclimatic envelope models based on the geographical distribution of species. Global Ecol. Biogeogr. 14:575584.

MacKenzie, D.I., 2006. Modeling the probability of resource use: the effect of, and dealing with, detecting a species imperfectly. J. Wildlife Manage. 70:367-374.

Mammola, S., Leroy, B., 2018. Applying species distribution models to caves and other subterranean habitats. Ecography 41:1194-1208.

Markle, T.M. and Kozak, K.H., 2018. Low acclimation capacity of narrow-ranging thermal specialists exposes susceptibility to global climate change. Ecol. evol. 8:4644-4656.

Mayor, S.J., Schneider, D.C., Schaefer, J.A., Mahoney, S.P., 2009. Habitat selection at multiple scales. Écoscience 16:238-247. 
Merow, C., Silander Jr, J.A., 2014. A comparison of Maxlike and Maxent for modelling species distributions. Methods Ecol. Evol. 5:215-225.

McCune, B., Keon, D., 2002. Equations for potential annual direct incident radiation and heat load. J. Veg. Sci. 13:603-606.

Milanovich, J.R., Peterman, W.E., Nibbelink, N.P., Maerz, J.C., 2010. Projected loss of a salamander diversity hotspot as a consequence of projected global climate change. PLoS ONE 5:e12189.

Moskwik, M., 2014. Recent elevational range expansions in plethodontid salamanders (Amphibia: Plethodontidae) in the southern Appalachian Mountains. J. Biogeogr. 41:19571966.

Moss, R.H., Edmonds, J.A., Hibbard, K.A., Manning, M.R., Rose, S.K., Van Vuuren, D.P., Carter, T.R., Emori, S., Kainuma, M., Kram, T., Meehl, G.A., 2010. The next generation of scenarios for climate change research and assessment. Nature 463:747-756.

Parra-Olea, G., Martinez-Meyer, E., De León, G.P., 2005. Forecasting climate change effects on salamander distribution in the highlands of central Mexico. Biotropica 37:202-208.

Phillips, S.J., Anderson, R.P., Schapire, R.E., 2006. Maximum entropy modeling of species geographic distributions. Ecol. Modell. 190:231-259.

Pough, F.H., Smith, E.M., Rhodes, D.H., Collazo, A., 1987. The abundance of salamanders in forest stands with different histories of disturbance. Forest Ecol. Manag. 20:1-9.

Quintero, I., Wiens, J.J. 2013. Rates of projected climate change dramatically exceed past rates of climatic niche evolution among vertebrate species. Ecol. Lett. 16:1095-1103. 
Rissler, L.J., Hijmans, R.J., Graham, C.H., Moritz, C., Wake, D.B., 2006. Phylogeographic lineages and species comparisons in conservation analyses: a case study of California herpetofauna. Am. Nat. 167:655-666.

Rissler, L.J., Smith, W.H., 2010. Mapping amphibian contact zones and phylogeographic break hotspots across the United States. Mol. Ecol. 19:5404-5416.

Royle, J.A., Chandler, R.B., Yackulic, C., Nichols, J.D., 2012. Likelihood analysis of species occurrence probability from presence-only data for modelling species distributions. Methods Ecol. Evol. 3:545-554.

Sutton, W.B., Barrett, K., Moody, A.T., Loftin, C.S., deMaynadier, P.G., Nanjappa, P., 2015. Predicted changes in climatic niche and climate refugia of conservation priority salamander species in the northeastern United States. Forests 6:1-26.

Suzuki, N., Olson, D.H., Reilly, E.C., 2008. Developing landscape habitat models for rare amphibians with small geographic ranges: A case study of Siskiyou Mountains salamanders in the western USA. Biodivers. Conserv. 17:2197-2218.

Title, P.O., Bemmels, J.B., 2018. ENVIREM: an expanded set of bioclimatic and topographic variables increases flexibility and improves performance of ecological niche modeling. Ecography 41:291-307.

Yackulic, C.B., Chandler, R., Zipkin, E.F., Royle, J.A., Nichols, J.D., Campbell Grant, E.H., Veran, S., 2013. Presence-only modelling using MAXENT: when can we trust the inferences? Methods Ecol. Evol. 4:236-243. 
Table 1. Variables considered (left) and used (right) for modeling the occurrence of the Cow Knob Salamander (Plethodon punctatus) across the species' distribution in eastern West Virginia and western Virginia, USA. All variables were standardized using a Z-score transformation prior to analyses.

\begin{tabular}{|c|c|c|c|}
\hline Variable & Abbrev & Variable & Abbrev \\
\hline \multicolumn{4}{|l|}{ Landscape Model } \\
\hline Canopy Cover & $\mathrm{CC}$ & Elevation & Elev \\
\hline \multirow[t]{4}{*}{ Lithology } & Lith & Heat load index & HLI \\
\hline & & Hillshade & Hill \\
\hline & & Slope & Slp \\
\hline & & Topographical position index & TPI \\
\hline \multicolumn{4}{|l|}{$\underline{\text { Climate niche model }}$} \\
\hline Mean diurnal range & Bio 2 & Mean annual temperature & AT \\
\hline Isothermality & Bio 3 & Precipitation of wettest quarter & Pwet \\
\hline Max temperature warmest month & Bio 5 & Precipitation of warmest quarter & Pwarm \\
\hline Min temperature coldest month & Bio 6 & Temperature seasonality & TS \\
\hline Annual temperature range & Bio 7 & Heat load index & HLI \\
\hline Mean temperature wettest quarter & Bio 8 & Hillshade & Hill \\
\hline Mean temperature driest quarter & Bio 9 & & \\
\hline Mean temperature coldest quarter & Bio 11 & & \\
\hline Annual precipitation & Bio 12 & & \\
\hline Precipitation of wettest month & Bio 13 & & \\
\hline Precipitation of driest month & Bio 14 & & \\
\hline Precipitation seasonality & Bio 15 & & \\
\hline Precipitation of driest quarter & Bio 17 & & \\
\hline Precipitation of coldest quarter & Bio 19 & & \\
\hline
\end{tabular}


Table 2. Model selection results to determine the optimal habitat suitability models for explaining the correlation between environmental variables and Cow Knob Salamander (Plethodon punctatus) occurrence across the species' distribution in eastern West Virginia and western Virginia, USA. The landscape models (left) consisted of topographic variables, while the climate niche models (right) consisted of climate and climate refugia variables. Variables included elevation (Elev), hillshade (Hill), heat load index (HLI), slope (Slp), topographical position index (TPI), mean annual temperature (AT), precipitation in the warmest quarter (Pwarm), precipitation in the wettest quarter (Pwet), temperature seasonality (TS). Model selection was based on Akaike's Information Criterion corrected for small sample size ( $\left.\mathrm{AIC}_{c}\right)$.

\begin{tabular}{lccccccc}
\hline & \multicolumn{3}{c}{ Landscape Models } & \multicolumn{5}{c}{ Climatic Niche Models } \\
Model & $\mathrm{AIC}_{c}$ & $\Delta \mathrm{AIC}_{c}$ & $\mathrm{w}_{i}$ & Model & $\mathrm{AIC}_{c}$ & $\Delta \mathrm{AIC}_{c}$ & $\mathrm{w}_{i}$ \\
\hline Elev, HLI, Hill, Slp & 6161.649 & 0 & 0.35 & $\mathrm{AT}, \mathrm{Hill}, \mathrm{HLI}$ & 6347.022 & 0 & 1 \\
Elev, HLI, Hill, Slp, TPI & 6162.413 & 0.764 & 0.239 & $\mathrm{AT}$, Hill, Pwarm & 6390.543 & 43.521 & 0 \\
Elev, HLI, Hill, TPI & 6162.423 & 0.774 & 0.238 & $\mathrm{AT}$, HLI, Pwarm & 6390.58 & 43.558 & 0 \\
Elev, HLI, Hill & 6163.046 & 1.397 & 0.174 & AT, Hill & 6391.465 & 44.443 & 0 \\
Elev, Hill, Slp & 6192.121 & 30.472 & 0 & AT, HLI, TS & 6391.755 & 44.733 & 0 \\
Elev, Hill, Slp, TPI & 6192.37 & 30.721 & 0 & AT, HLI, Pwet & 6393.561 & 46.539 & 0 \\
Elev, Hill & 6197.916 & 36.267 & 0 & AT, HLI & 6447.7 & 100.678 & 0 \\
Elev, Hill, TPI & 6199.521 & 37.872 & 0 & AT, Pwarm & 6507.522 & 160.5 & 0 \\
Elev, HLI & 6231.337 & 69.688 & 0 & AT, TS & 6507.56 & 160.538 & 0 \\
Elev, HLI, TPI & 6233.406 & 71.757 & 0 & AT & 6507.573 & 160.551 & 0 \\
E, TPI, Slp & 6274.762 & 113.113 & 0 & AT, Pwet & 6509.601 & 162.579 & 0 \\
Elev & 6277.338 & 115.689 & 0 & Pwet & 6907.564 & 560.542 & 0 \\
Elev, TPI & 6279.286 & 117.637 & 0 & Pwarm & 6932.333 & 585.311 & 0 \\
Elev, HLI, Slp & 6590.179 & 428.53 & 0 & TS & 7005.682 & 658.66 & 0 \\
Hill & 6965.741 & 804.092 & 0 & Null model & 7986.234 & 1639.212 & 0 \\
TPI & 6971.586 & 809.937 & 0 & & & & \\
HLI & 7007.445 & 845.796 & 0 & & & & \\
Slp & 7016.254 & 854.605 & 0 & & & & \\
Null model & 7986.234 & 1823.821 & 0 & & & &
\end{tabular}


Table 3. Parameter estimates ( $\beta$ ) and standard errors (SE) from the best approximating landscape model (left) and climate niche model (right) explaining the correlation between habitat variables and Cow Knob Salamander (Plethodon punctatus) occurrence across the species' distribution in eastern West Virginia and western Virginia, USA.

\begin{tabular}{lccccccc}
\hline & \multicolumn{3}{c}{ Landscape Model } & \multicolumn{4}{c}{ Climatic Niche Model } \\
Variable & $\beta$ & $\mathrm{SE}$ & $\mathrm{P}(>|\mathrm{z}|)$ & Variable & $\beta$ & $\mathrm{SE}$ & $\mathrm{P}(>|\mathrm{z}|)$ \\
\hline Intercept & -6.6840 & 0.5893 & $<0.001$ & Intercept & -5.702 & 0.7568 & $<0.001$ \\
Elev & 1.5658 & 0.0835 & $<0.001$ & AT & -1.401 & 0.0871 & $<0.001$ \\
HLI & -0.3714 & 0.0690 & $<0.001$ & Hill & 0.794 & 0.0937 & $<0.001$ \\
Slp & 0.0906 & 0.0743 & 0.223 & HLI & -0.437 & 0.0767 & $<0.001$ \\
Hill & 0.6409 & 0.0873 & $<0.001$ & & & & \\
\hline
\end{tabular}


1 Table 4. Summary statistics for projected changes in mean annual temperature, and resulting

2 percentage changes in species occurrence probability classes for the Cow Knob Salamander

3 (Plethodon punctatus) across the species' distribution in eastern West Virginia and western

4 Virginia, USA. Low occurrence probability habitat is defined by the minimum training presence

5 threshold, where all known locations were correctly predicted by the model, while high

6 occurrence probability habitat is defined by probability values that are above the 10 fixed

7 cumulative (i.e. the value that results in a $10 \%$ omission in training data).

\begin{tabular}{|c|c|c|c|c|}
\hline Climate condition & Mean temp increase ${ }^{\circ} \mathrm{C}$ & $\%$ Not suitable & \% Low probability & \% High probability \\
\hline Baseline & NA & 6.5 & 66.9 & 26.8 \\
\hline \multicolumn{5}{|l|}{$2050 \mathrm{RCP} 4.5$} \\
\hline median & 1.56 & 74.3 & 23.7 & 2.1 \\
\hline$\left(10^{\text {th }}, 90^{\text {th }}\right.$ percentiles $)$ & $(0.99,2.31)$ & $(47.2,91.2)$ & $(46.4,8.7)$ & $(6.4,0.2)$ \\
\hline \multicolumn{5}{|l|}{$2050 \mathrm{RCP} 8.5$} \\
\hline median & 2.15 & 88.7 & 10.9 & 0.4 \\
\hline$\left(10^{\text {th }}, 90^{\text {th }}\right.$ percentiles $)$ & $(1.2,3.18)$ & $(66.4,98.3)$ & $(30.3,1.7)$ & $(3.3,0.0)$ \\
\hline \multicolumn{5}{|l|}{$2100 \mathrm{RCP} 4.5$} \\
\hline median & 2.07 & 86.9 & 12.5 & 0.5 \\
\hline$\left(10^{\text {th }}, 90^{\text {th }}\right.$ percentiles $)$ & $(1.31,3.06)$ & $(63.1,97.6)$ & $(33.0,2.4)$ & $(4.0,0.0)$ \\
\hline \multicolumn{5}{|l|}{$2100 \mathrm{RCP} 8.5$} \\
\hline median & 5.14 & 100 & 0.0 & 0.0 \\
\hline$\left(10^{\text {th }}, 90^{\text {th }}\right.$ percentiles $)$ & $(3.26,7.60)$ & $(98.5,100)$ & $(1.5,0.0)$ & $(0.0,0.0)$ \\
\hline
\end{tabular}

8 

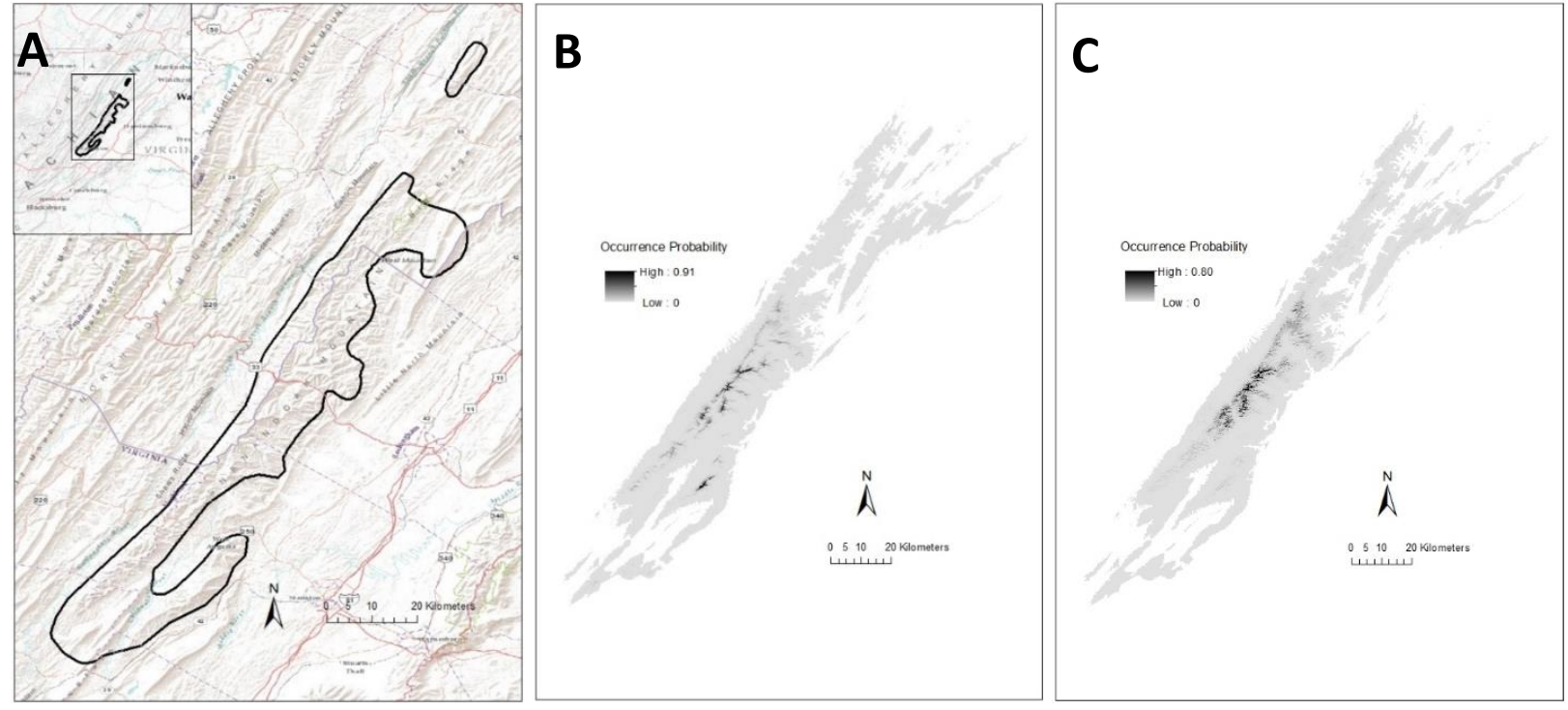

Fig. 1. A) General contemporary distribution map for the Cow Knob Salamander (Plethodon punctatus) along the West Virginia and Virginia border in the Valley and Ridge Province, USA. B) Projected contemporary occurrence probability for the Cow Knob Salamander based on the top landscape model that used the additive effects elevation, heat load index (HLI), hillshade, and slope. C) Projected contemporary occurrence probability for the Cow Knob Salamander based on the top climate niche model that used the additive effects of mean annual temperature, HLI, and hillshade. 


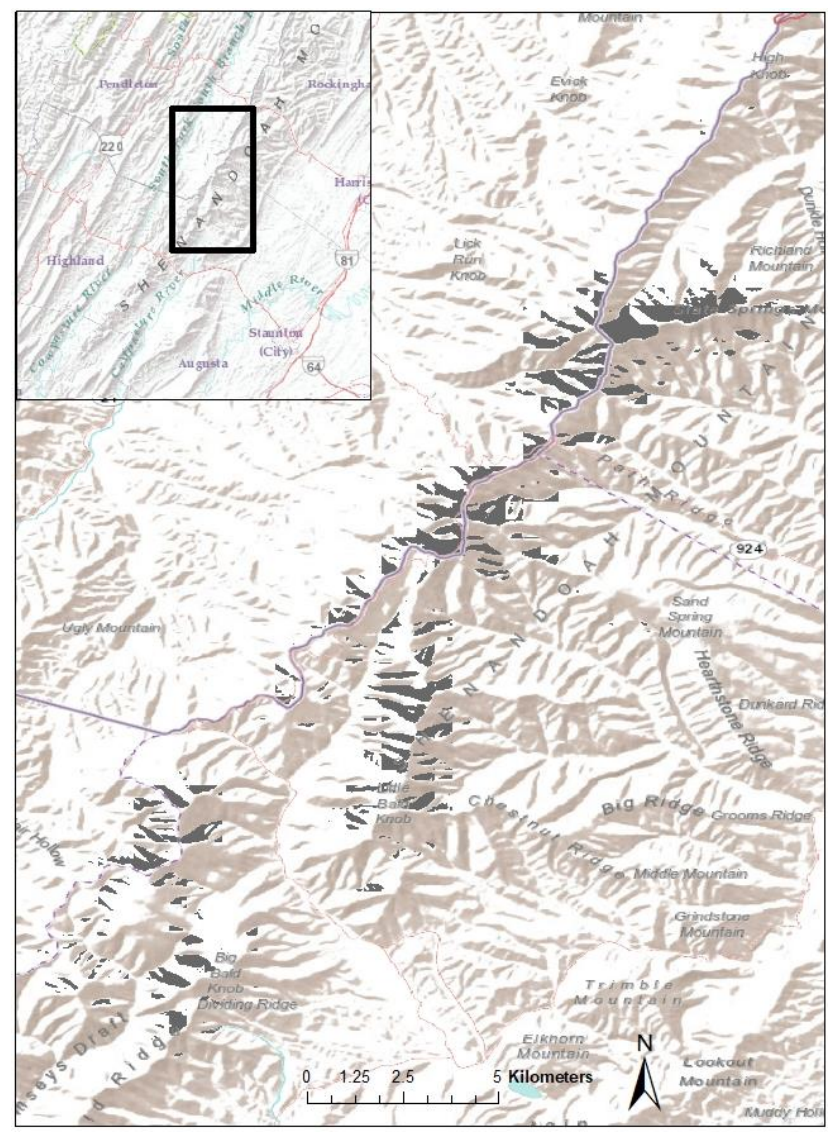

Fig 2. Map of climate refugia (high occurrence probability habitat [dark shaded areas]) for the Cow Knob Salamander (Plethodon punctatus) in the year 2100 using the median of an ensemble of 31 climate models under the 4.5 representative concentration pathway $(\mathrm{RCP})$ scenario that forces a gradual reduction in greenhouse gas emissions after the year 2030. This climatic niche model used the additive effects of mean annual temperature, HLI (heat load index), and hillshade. 


\title{
CHAPTER 3
}

\section{INFLUENCE OF PRESCRIBED FIRE AND FOREST STRUCTURE ON WOODLAND SALAMANDER ABUNDANCE IN THE CENTRAL APPALACHIANS}

\begin{abstract}
Prescribed fire is used in the central Appalachians to promote and maintain mixed-oak and pine forests, create open forest conditions, and improve habitat for wildlife. Relatively little research has been conducted on responses of terrestrial salamander populations to fire, with previous investigations finding a range of responses from neutral to negative depending on geography, species, and fire-severity. We examined woodland salamander (genus Plethodon) population responses to habitat management using prescribed fire on Shenandoah Mountain in the George Washington National Forest in West Virginia and Virginia, USA. We chose this study area to focus on responses of the Cow Knob Salamander (P. punctatus), a talus habitat specialist and species of high conservation concern, but also examined responses of the Eastern Red-Backed Salamander ( $P$. cinereus $)$, a widespread habitat generalist. Three of the burn units were subjected to two low-severity burns and one unit was burned five times with ca. $40 \%$ tree mortality. Using a combination of nighttime visual encounter surveys and coverboard surveys, we compared terrestrial salamander abundance and body condition in unburned and burned habitat. We also measured habitat characteristics at sampling sites to determine if prescribed burn histories were correlated with habitat conditions important to woodland salamanders. We found abundance for P. punctatus was lower in sites with less canopy cover and sites that were in burned areas. Abundance of $P$. cinereus was also positively correlated with canopy cover, and there was evidence that abundance differed by burn-severity, with lowest abundances at high burn-severity
\end{abstract}


sites. We found that mean and median body condition index (BCI) score was higher for $P$.

punctatus and lower for P. cinereus on the West Virginia side of Shenandoah mountain, and lower in burned habitat for both species. However, the most parsimonious models did not contain the burn predictor, and the coefficient confidence intervals overlapped 0. Management using prescribed fire altered microhabitat conditions that are important for woodland salamanders, such as canopy cover, leaf litter depth, and vegetation cover. Our study supports that, at least in the short-term, habitat management using repeated prescribed fires can result in reduced abundances of woodland salamanders in the central Appalachians.

\section{Introduction}

In the central Appalachian region of the eastern United States, prescribed fire is used by land managers as a tool to maintain and restore mixed-oak and pine forests, create and maintain open forest and early successional conditions, and decrease fuel loads to reduce the intensity of wildfires (Lafon et al., 2005). Mixed-oak (Quercus spp.) and pine (Pinus spp.) forests are adapted to low-intensity, high-frequency fires that were set by native Americans and caused by lightning strikes before European settlement (Aldrich et al., 2010, 2014). During the industrial logging period in the late 19th and early 20th centuries, high-intensity, stand-replacing fires became common, followed by a period of fire suppression that began in ca. 1930 (Brose et al., 2001; Lafon et al., 2017). Massive wildfires during this period shifted public opinion to view fire as a detrimental force and fire suppression became a widespread policy and one of the first priorities for the U.S. Forest Service (USFS; Brose et al., 2001). Fire suppression allowed for succession from mixed-oak to forests dominated by shade-tolerant, fire-sensitive species, because oaks are not adapted to grow in heavily shaded forests (Brose et al., 2001). After 
decades of fire suppression, the importance of fire as a natural disturbance in Appalachian oak and pine forests became apparent (e.g. Nowacki and Abrams, 2008). Consequently, in the early 1970s, natural resource managers began using prescribed fire as a forest management tool in the central Appalachians, and it is now used for restoration and maintenance of fire-dependent ecosystems on public lands in the region (Lafon et al., 2005).

Prescribed fires allow for the regeneration of mixed-oak stands through removal of thinbarked shrubs and trees that compete for sunlight, reduction of leaf litter that prevents seedling establishment, decreased insect predation on acorns, and increased acorn caching by wildlife (Van Lear and Watt, 1993; Barnes and Van Lear, 1998). Further, seed banks of non-oak species often decline after prescribed burns (Schuler et al., 2010). The greatest benefits of prescribed burns for oak regeneration generally come after repeated burns and when fires occur during the growing season (Brose et al., 2013). Fire is also important to Table Mountain pine (Pinus pugens) and pitch pine ( $P$. rigida), two species that are native to the southern and central Appalachians, because it opens their serotinous cones to release seeds (Elliot et al., 1999; Welch et al., 2000). Prescribed fires can also increase the diversity and abundance of understory shrubs, forbs, and grasses that provide food and cover resources for wildlife (Elliott et al., 1999; Barrioz et al., 2013).

While prescribed fires promote maintenance and restoration of oak and pine stands in the central Appalachians, relatively little research has been conducted on wildlife community responses to fire in the region. Research is needed to examine the responses of wildlife species to different fire regimes (i.e., fire season, intensity, size, and return interval). Further, local, speciesspecific research is needed because the scale of inference is limited in fire-wildlife research due to variation in fire regimes, site-level habitat characteristics, and biotic interactions (Pilliod et al., 
2003; Fontaine and Kennedy, 2012; Brown et al., 2014; O’ Donnell et al., 2016). Also, wildlife species respond differentially to fire based on their ecology; some species in the region such as Turkey (Meleagris gallopavo; McCord et al., 2014), White-Tailed Deer (Odocoileus virginianus; Lashley et al., 2011), and some reptiles (e.g. Keyser et al., 2004; Greenberg et al., 2018; Hromada et al., 2018) appear to benefit from prescribed burns, but negative impacts have been noted for other species such as the Eastern Box Turtle (Terrapene carolina; Howey and Roosenburg, 2013).

The Appalachians are a global biodiversity hotspot for salamanders (Milanovich et al., 2010). Woodland salamanders (genus Plethodon) are an integral component of forest ecosystems, their biomass often exceeds that of birds, small mammals, and deer (Burton and Likens, 1975), and due to their abundance, they affect invertebrate community composition and contribute to forest nutrient cycling (Semlitch et al., 2014; Best and Welch, 2014). Given their ecological importance and the unique biodiversity salamanders provide in the Appalachians, it is important to understand the responses of salamanders to fire in this region. For woodland salamanders, previous investigations found a range of responses that varied among species, geographic region, microhabitat characteristics, size class, and fire regime (e.g. Matthews et al., 2010; Ford et al., 2010; O’ Donnell et al., 2015; Hromada et al., 2018; Gade et al., 2019). While the majority of previous studies did not conclude that prescribed fire significantly influenced salamander abundance, declines in abundance were apparent when multiple burns resulted in tree mortality (Matthews et al., 2010), and when prescribed fire was combined with shelterwood harvest or clearcuts (Hocking et al., 2013; Mahoney et al., 2016), suggesting prescribed fire may negatively impact salamander populations when it causes, or is combined with, a reduction in canopy cover. 
The effects of fire on salamanders are likely indirect; terrestrial salamanders are fossorial, so direct mortality from fire is probably rare (Renken, 2006; O’Donnell et al., 2016). In the short-term, prescribed fires can affect microhabitat characteristics of a forest by reducing canopy cover, coarse woody debris, leaf litter, and duff, thus creating drier soil conditions and in some cases increasing soil hydrophobicity (Certini, 2005; Lafon et al., 2007; Matthews et al., 2010; Mahoney et al., 2016). Plethodontid salamanders are sensitive to changes in microhabitat characteristics that affect moisture or temperature, such as leaf litter depth and canopy cover, because they are lungless and must keep their skin moist to perform cutaneous respiration for gas exchange (Maerz et al., 2009).

Previous studies on the effects of prescribed fire on woodland salamanders have mostly focused on the short-term effects of a single burn. However, repeated burns with relatively short fire intervals are often needed to achieve management objectives in central Appalachia (Brose et al., 2013). Thus, it is important to understand how woodland salamander populations respond to multiple prescribed burns and the resulting changes in forest structure characteristics.

Additionally, population-level responses to a reduction in canopy cover can take several years to be realized. For example, Green and Waldrop (2008) concluded that abundance of woodland salamanders was not affected by a mechanical fuel reduction and prescribed burn that resulted in tree mortality and reduced canopy cover; however, salamander abundance was lower at these sites a few years later following a second prescribed burn, and lower than a treatment that was burned twice with no mechanical fuel reduction (Mathews et al., 2010). Also, Gade et al. (2019) found a decline in the number of juvenile Red-Legged Salamanders (P. shermani) 18 months post-wildfire when compared to the same sites 6 months post-wildfire. 
The purpose of this study was to examine effects of fire history and forest structure characteristics on abundance and body condition of woodland salamanders in the central Appalachian region. Specifically, we focused on the Cow Knob Salamander (Plethodon punctatus), a high elevation endemic species of conservation concern, and sympatric populations of the common and widely distributed Eastern Red-Backed Salamander (Plethodon cinereus). Most of the distribution of $P$. punctatus occurs on Shenandoah Mountain within the George Washington National Forest (GWNF; Highton, 1972), and prescribed fire is heavily used for forest vegetation management in the GWNF and adjacent Jefferson National Forest (USFS, 2014). The results of this study will allow managers to predict how future fires will affect terrestrial salamanders in the study area, and thus to balance vegetation-related goals with the promotion of robust salamander populations.

\section{Methods}

\subsection{Study area}

We conducted our study at high elevations (> $1075 \mathrm{~m}$ ) on Shenandoah Mountain in the GWNF in eastern West Virginia and western Virginia, USA (precise locations withheld due to the conservation status of $P$. punctatus). This area is in the Valley and Ridge Province, the driest region in the central Appalachians (Lafon and Grissino-Mayer, 2007). Dominant overstory trees included white oak (Quercus alba), northern red oak (Q. rubra) chestnut oak (Q. montana), yellow birch (Betula alleghaniensis), eastern hemlock (Tsuga canadensis), and red maple (Acer rubrum). The understory consisted mostly of striped maple (A. pensylvanicum) and mountain laurel (Kalmia latifolia). Much of the study area consisted of steep talus slopes. 
The USFS uses prescribed fire as a management tool on the GWNF to create open forest and early successional conditions, and to protect ecosystem components and wildland-urban interfaces from severe wildfires by decreasing fuel loads (USFS, 2014; Lorber et al., 2018). This management plan strives to avoid burning more mesic forests where oaks are not a major component, and when burning is necessary, to allow only low-intensity fires (USFS, 2014). In order to achieve this, they have a target fire-return interval of 5-15 years in oak-dominated stands, and 3-9 years in pine-dominated stands, with ca. 4,850-8,100 ha burned annually (USFS, 2014). Burns are typically conducted at the end of the dormant season or beginning of the growing season in late April or early May (Lorber et al., 2018).

We restricted our study area to accessible locations in the GWNF within the known distribution of P. punctatus. We sampled 4 burn units: North New Road (NNR) was ca. 1,760 ha and burned in 2012 and 2015, Little Fork (LF) was ca. 790 ha and burned in 2000 and 2008, Hone Quarry (HQ) was ca. 525 ha and burned in 1999, 2002, 2010, 2013, and 2018, and Hone Quarry 2 (HQ2) was ca. 1010 ha and burned in 2013 and 2018 (Fig. 1). Most of these burns were low-severity, however, the first burn for HQ resulted in ca. $40 \%$ overstory tree mortality (Lorber et al., 2018).

For each burn unit, we chose general sampling locations based on the presence of adjacent unburned areas (i.e., not burned since initiation of the GWNF fire program) that were similar in aspect, elevation, and talus level to burned plots. After delineating the general sampling locations, we selected sampling sites using a stratified random approach, where sites were at least $35 \mathrm{~m}$ from any roads to minimize edge effects (Semlitsch et al., 2007), no more than $100 \mathrm{~m}$ from roads to allow for ease of access, and $40 \mathrm{~m}$ apart to ensure each site was spatially independent with respect to typical woodland salamander movement distances 
(Petranka, 1998). We ensured that all burn units had signs of fire (i.e. fire scars, burned woody debris, or leaf litter) within $10 \mathrm{~m}$ of each survey site. Each burn unit and adjacent control habitat contained from 6-10 survey sites, for a total of 61 sites. Sites consisted of 5 x $5 \mathrm{~m}$ plots of land.

\subsection{Salamander surveys}

We used a combination of nighttime visual encounter surveys (VES) and nighttime coverboard surveys to sample salamanders at each site. Nighttime VES was previously found to be more effective than daytime surveys using coverboards and natural cover objects for detecting $P$. punctatus because in talus habitat, where they are most abundant, they are typically not on the surface during the daytime (Flint, 2004; Flint and Harris, 2005). In contrast, previous studies have found daytime coverboard surveys to be effective for P. cinereus (Moore, 2005; Hessed, 2012). We acknowledge that coverboard surveys are potentially less effective at night, they were used here only as supplements to VES. At the center of each site, we placed 4 coverboards (2.5 $\mathrm{cm}$ thick x $15 \mathrm{~cm}$ wide x $30 \mathrm{~cm}$ long) made from untreated tulip poplar (Liriodendron tulipifera).

Each site was sampled between 2 and 5 times within a single survey year, from 22 April to 9 October 2017 or 16 May to 23 September 2018, for a total of 197 survey events. We surveyed salamanders after dusk (i.e. starting at least 30 minutes after civil twilight to a maximum of seven hours after dusk). All surveys took place within 24 hours of a rain event to maximize the probability of salamander surface activity and thus detection probability (Grover, 1998; Flint and Harris, 2005). We employed area constrained surveys that lasted 7-18 minutes (mean = 12 minutes), depending on habitat complexity. We only counted salamanders visible on the surface or under coverboards, no natural cover objects were flipped in order to preserve the 
integrity of the lichen and moss-covered talus habitat used by P. punctatus (Flint and Harris, 2005).

\subsubsection{Salamander body condition}

When possible, we hand-captured and performed standard measurements on detected salamanders. We recorded snout-vent-length (SVL) to the nearest $1 \mathrm{~mm}$ and weight to the nearest $0.1 \mathrm{~g}$. We used a salamander stick to maximize accuracy of SVL measurements (Margenau et al., 2018). We created body condition indices (BCI) for P. punctatus and $P$. cinereus by regressing (log) snout-vent-length (SVL) on (log) weight (Schulte-Hostedde et al. 2005). Positive residuals indicate a greater than average weight for a given SVL, and vice versa. We did not include gravid females or salamanders missing portions of their tails in BCI analyses.

\subsection{Model predictors}

Our abundance predictors included fire history, forest structure, geological, and topographic variables. The fire history variables we tested were burn status (burned or unburned), burn class (unburned, low-severity, high-severity), and time-since-burn. We measured overstory canopy cover at the center of each site using a convex spherical densiometer at chest height, with measurements taken in 4 directions and averaged. We recorded the percent ground cover of leaves, moss, and vegetation at each site using ocular estimation. We measured leaf litter depth from the surface of the leaf litter to the top of the soil, duff layer, or rocks. We took one leaf litter depth measurement in the center of each quadrant and used the mean of these values. We did not measure the duff layer because most sites did not have duff in the talus habitat. We modified a talus ranking system that has been used previously in our study area that 
is based on the relative amount of rocks, soil, and spacing present (Downer, 2009). We ranked talus habitat on a scale from 0 to 5 , where 0 is soil with few or no rocks present, 2.5 is a mixture of soil and rocks with some cracks and crevices present, and 5 is rocks with no soil and abundant cracks and crevices between the rocks. We also created a binary talus variable to assess if the presence of talus is more important than the amount of cracks and crevices present. Sites were classified sites as talus if it received a talus ranking score greater than 2.5.

We included state (i.e. West Virginia [WV] or Virginia), which corresponded to side of the mountain, as a covariate because previous research found $P$. punctatus was more abundant on the western side of the mountain (i.e., WV), likely due to wetter conditions within the study area (Flint and Harris, 2005). We obtained a $1 / 3$ arc second (ca. $8 \mathrm{~m}^{2}$ at $39^{\circ}$ North) digital elevation model (DEM) from the U.S. Geological Survey National Elevation Dataset and derived 3 variables from this layer: Heat Load Index (HLI), slope, and hillshade. HLI is a measurement of the potential heat and incident radiation a site receives due to aspect and slope (McCune and Keon, 2002). This index assigns higher values for locations with a southwest aspect because they receive higher maximum temperatures from the afternoon sun. The following equation rescales aspect to a scale from 0 for cooler northeast-facing slopes, to 1 for warmer southwest-facing slopes:

$$
\text { Heat Load Index }=\frac{1-\cos (\theta-45)}{2}
$$

where $\theta=$ aspect in degrees east of north. HLI also accounts for the steepness of a south-facing slope because steeper slopes dry out faster (McCune and Keon, 2002). 


\subsection{Data analyses}

\subsubsection{Forest structure characteristics}

We assessed relationships between fire history and forest structure characteristics using redundancy analyses (RDA). RDA is a multivariate analysis that is an extension of principal components analysis (PCA) to include explanatory variables. We chose RDA over canonical correspondence analysis (CCA) because our gradient lengths were short $(<2$; Legendre and Legendre, 2012). We conducted global ANOVA permutation tests to determine if forest structure characteristics differed based on burn class and time-since-burn. We used the package vegan (version 2.5-4) in program R (version 3.5.1) for RDA analyses.

\subsubsection{Salamander abundance}

For woodland salamanders, often only a small proportion of the population is active on the surface and available for detection due to their unique physiological requirements and activity patterns (Bailey et al., 2004). Thus, it is important to consider parameters that affect detectability when estimating salamander abundance (O'Donnell and Semlitch, 2015). To estimate abundance and detectability parameters, we analyzed repeated counts using singleseason, closed population $N$-mixture models (Royle, 2004). $N$-mixture models account for variations in detection probability using temporally and spatially replicated surveys.

For each species, we tested a Poisson, Zero-inflated Poisson (ZIP), and negative binomial (NB) distribution for the abundance submodels. The negative binomial models did not converge, which is a common issue when detection probabilities are low (Dennis et al., 2015). We selected the ZIP distribution because it resulted in a lower Quasi Akaike's information criterion, corrected for small sample $\left(\mathrm{QAIC}_{c}\right)$ score for both species. To assess model goodness-of-fit, we used the 
most complex candidate model and a 1,000-replication parametric bootstrap of the Pearson chisquare statistic (Kéry and Royle, 2016). Our c-hat values for P. punctatus were 1.46, 1.38, and 1.32, and for $P$. cinereus were $1.77,1.88$, and 1.73 for the geological, burn history, and forest structure models respectively, indicating some overdispersion. To account for this overdispersion, we ranked candidate models using QAIC $($ Symonds and Moussalli, 2011).

We used a $\mathrm{QAIC}_{c}$ model selection approach to determine the most important predictors of woodland salamander abundance and detection probability $(p)$. We first selected the most parsimonious $p$ submodels using weather and temporal variables collected during each survey. We tested air temperature $\left({ }^{\circ} \mathrm{C}\right)$, relative humidity, time since sunset, and wind speed $(\mathrm{kph})$. We retained the most parsimonious $p$ submodel for all further analyses. We then selected the most parsimonious model for geological-topographic variables (i.e., state, talus, elevation, HLI, hillshade, slope), which were also retained for all further analyses. We conducted separate model selection analyses for fire history and forest structure characteristics, to determine if there was an overall effect of fire and if abundance was strongly related to the forest structure characteristics we measured, respectively. During preliminary analyses we detected model convergence issues for some variable combinations when $>4$ abundance covariates were included, and thus we restricted our model selections to include a maximum of 4 covariates. We considered variables to have some support if $\Delta \mathrm{QAIC}_{c}<7$ (Burnham et al. 2011). We conducted $N$-mixture and model selection analyses using the packages unmarked (version 0.12-2) and AICcmodavg (version 2.11) in program $R$. 


\subsubsection{Salamander body condition}

We used linear regression models with a Gaussian distribution to assess effects of fire history and forest structure characteristics on salamander BCI (Zuur et al., 2009). We used graphical diagnostics (i.e., quantile-quantile and residual plots) to assess model fit, which indicated our data satisfied the assumptions of normality and heteroscedasticity. As with the abundance analyses, we first fit models with the most parsimonious geological-topographical variables; we then retained these variables for separate fire history and forest structure analyses. We only tested variables we hypothesized would have an impact on BCI.

\section{Results}

\subsection{Forest structure characteristics}

The RDA indicated a significant relationship between burn class and forest structure characteristics $(\mathrm{F}=7.09, \mathrm{P}<0.001)$, and between time-since-burn and forest structure characteristics $(\mathrm{F}=7.52, \mathrm{P}<0.001)$. Canopy cover, moss cover, leaf cover, and litter depth showed a strong positive correlation with unburned sites, and a strong negative correlation with high-severity fire sites, while vegetation cover showed the opposite relationship. Low-severity sites had intermediate values for forest structure characteristics (Fig. 2). Canopy cover and moss cover were positively correlated, forest structure cover was negatively correlated, and litter depth and leaf cover were not strongly correlated with time-since-burn.

\subsection{Salamander abundance}

We captured a total of 296 salamanders, including $80 P$. punctatus, 213 P. cinereus, and 3 Eastern Newts (Notophthalmus viridescens). We detected P. punctatus and P. cinereus at 31 
and 54 sites, respectively. All locations where we found P. punctatus were on, or within $100 \mathrm{~m}$ of, talus habitat. We found $0 \%$ of $P$. punctatus and $3.8 \%$ of $P$. cinereus under coverboards during our study. Detection probability increased with temperature for both $P$. punctatus and $P$. cinereus (Fig. 3). Mean estimated abundance per site was 6.1 and 19.0 for $P$. punctatus and $P$. cinereus, respectively (Fig. 4).

For the geological-topographic model selection, abundance of $P$. punctatus was best predicted by state and the binary talus variable, while $P$. cinereus abundance was best predicted by state (Table 1), with abundances higher on the WV side of the mountain for both species, and higher in talus for P. punctatus (Table 2). For the fire history model selection, the most parsimonious model for $P$. punctatus included burn status as a predictor of abundance (Table 1), and abundance was negatively associated with burned sites (Table 2), though the null model also received some support. For $P$. cinereus, the most parsimonious model was the null model, however there was support for both burn class and burn status as a predictor of abundance (Table 1), with lowest abundances in the high-severity class and highest abundances in the unburned class (Table 2). Canopy cover was the most supported forest structure predictor for abundance of both $P$. punctatus and $P$. cinereus (Table 1 ), with abundances positively correlated with canopy cover (Table 2). Vegetation cover was also included in the most parsimonious forest structure model for $P$. cinereus, with a positive correlation. All forest structure variables tested had some support as predictors of abundance for both species (Table 1).

\subsection{Salamander body condition}

For the geological-topographic BCI model selection, the most parsimonious model for both species contained state as a predictor (Table 3), with $P$. punctatus $\mathrm{BCI}$ being higher, and $P$. 
cinereus BCI being lower, on the WV side of the mountain (Table 4, Fig. 5a). For the fire history model selection, burn status had some support for both species, but the null models received higher support (Table 3). Mean and median BCI was lower in burned habitat for both species (Fig. 5b). For the forest structure model selection, the most parsimonious model included leaf cover for both species, and vegetation cover for $P$. cinereus (Table 3 ). BCI was negatively correlated with leaf depth for $P$. punctatus, and negatively correlated with leaf cover and vegetation cover for $P$. cinereus.

\section{Discussion}

We found abundance for both $P$. punctatus and $P$. cinereus was negatively associated with burned habitat, suggesting that, at least in the short-term, prescribed fires may result in reduced habitat quality for woodland salamander populations on Shenandoah Mountain. Results of the burn class model for $P$. cinereus indicate that effects on abundance may increase with fireseverity, which also corresponded to larger effects on forest structure characteristics. In particular, canopy cover was negatively associated with burned habitat, and this relationship was the strongest for the high-severity HQ burn unit (see Fig. 2). Canopy cover was the strongest forest structure predictor of abundance for both species, with leaf litter depth, leaf cover, and vegetation cover also receiving some support. In spite of the inverse relationship between canopy cover and vegetation cover (Fig. 2), P. cinereus abundance was positively correlated with both variables, suggesting increased vegetation cover from prescribed fire could buffer the effects of canopy loss for this species. Based on our results and additional studies (e.g. Matthews et al., 2010; Mahoney et al., 2016), it appears that the greatest effects of prescribed fire on woodland salamander abundance occur when canopy cover is reduced. 
Canopy cover and leaf litter could be particularly important for $P$. punctatus because of their talus habitat association and the climate of this region. The surface of talus habitat dries out faster than areas with soil because water percolates through the rubble, spaces between the rocks allow for air flow and quicker evaporation, and there is reduced capillarity with coarser particles (McCune, 1977; Pérez, 1998). Reductions in canopy cover and leaf litter would increase the rate of surface drying and could limit the amount of time salamanders can be active on the surface for foraging or breeding (O’Donnell et al., 2016). Prescribed fire in the GWNF tends to create more canopy gaps on sites with a higher HLI (Lorber et al., 2018), meaning fire creates more canopy gaps on aspects where $P$. punctatus is likely to be absent or less abundant (Buhlmann et al., 1988; USFS, 2014). However, even though $P$. punctatus is less abundant on these aspects, we found them at several sites on a high-elevation, south-facing talus slope.

Our results indicate that abundances of $P$. punctatus were more than twice as high in talus habitat on the WV side of the mountain $\left(0.41\right.$ per $\left.^{2}\right)$ as the VA side of the mountain $(0.15$ per $\mathrm{m}^{2}$ ). This finding is congruent with a previous capture-recapture study for P. punctatus (Flint and Harris, 2005). Our abundance estimates also overlap the abundances estimated by Flint and Harris (2005) who found 0.35 and 0.65 individuals per $\mathrm{m}^{2}$ in their surveys that were confined to perceived optimal habitat on north-facing talus slopes. For our best $P$. punctatus sites, estimated abundances were similar to, or higher than Flint and Harris (2005). Our finding that BCI was greater for $P$. punctatus on the $\mathrm{WV}$ side of the mountain is also congruent with Flint and Harris (2005). Greater abundance and BCI of $P$. punctatus on the WV side of the mountain could be due to wetter conditions and habitat differences (Flint and Harris, 2005). Our habitat measurements indicated that our sites on the west side of the mountain had greater moss cover, 
suggesting these sites may be wetter. Additionally, the WV side of the mountain appears to have more and larger talus areas, which could allow for greater habitat patch size and connectivity.

Due to the vulnerability of $P$. punctatus to climate change (Chapter 2) and its poor acclimation ability to warmer temperatures (Markle et al., 2018), a closed canopy could be an important component of climate refugia for this species. In order to maintain P. punctatus populations, land managers should consider managing for a closed canopy forest where this species is known to occur. Potential concerns for negative effects of prescribed fire management on $P$. punctatus population viability might be eased if fire is concentrated on drier sites where the species is less abundant and fire was historically more common (Harper et al., 2016), and if fires that occur in more suitable habitat are low-intensity and do not result in overstory tree mortality. However, we note the drier ridges of Shenandoah Mountain are occupied by the endemic Shenandoah Mountain Salamander (Plethodon virginia), and to our knowledge no studies have investigated effects of habitat management using fire on this species. We emphasize that, while we did detect a difference in abundance based on Burn Status, our study does not indicate that burning has resulted in local extirpations of $P$. punctatus. This study contributes to the general ecological knowledge of $P$. punctatus by quantifying relationships between habitat characteristics and abundance/BCI, and provides agencies with information that can be used for management of the species.

\section{Acknowledgments}

This work was supported by a grant from the U.S. Forest Service Northern Research Station. We thank C. Croy, S. Croy, and U.S. Forest Service George Washington-Jefferson National Forest staff for their assistance with study design and for providing management and spatial data. We 
thank W. Flint for his valuable insights into the ecology and sampling methods for P. punctatus, and for his assistance with surveys. We thank S. Crayton and J. Newman for assisting with surveys, and L. Rucker for help setting up field sites.

\section{References}

Aldrich, S.R., Lafon, C.W., Grissino-Mayer, H.D., DeWeese, G.G., Hoss, J.A., 2010. Three centuries of fire in montane pine-oak stands on a temperate forest landscape. Appl. Veg. Sci. 13:36-46.

Aldrich, S.R., Lafon, C.W., Grissino-Mayer, H.D., DeWeese. G.G., 2014. Fire history and its relations with land use and climate over three centuries in the central Appalachian Mountains, USA. J. Biogeogr. 41:2093-2104.

Bailey, L.L., Simons, T.R., Pollock. K.H., 2004. Estimating detection probability parameters for Plethodon salamanders using the robust capture-recapture design. J. Wildlife Manage. $68: 1-13$.

Barrioz, S., Keyser, P., Buckley, D., Buehler, D., Harper, D., 2013. Vegetation and avian response to oak savanna restoration in the mid-south USA. Am. Midl. Nat. 169:194-213.

Barnes, T.A., Van Lear. D.H., 1998. Prescribed fire effects on advance regeneration in mixed hardwood stands. South. J. Appl. For. 22:138-142.

Best, M.L., Welsh Jr, H.H., 2014. The trophic role of a forest salamander: impacts on invertebrates, leaf litter retention, and the humification process. Ecosphere 5:1-19.

Brose, P., Schuler, T., Van Lear, D., Berst. J., 2001. Bringing back fire: the changing regimes of the Appalachian mixed-oak forest. J. Forest. 99:30-35. 
Brose. P.H,, Dey, D.C, Phillips, R.J., Waldrop. T.A., 2013. A meta-analysis of the fire-oak hypothesis: does prescribed burning promote oak reproduction in eastern North America? Forest Sci. 50:322-334.

Brown, D.J., Nowlin, W.H., Ozel, E., Mali, I., Episcopo, D., Jones, M.C., Forstner., M.R.J., 2014. Comparison of short term low, moderate and high severity fire impacts to aquatic and terrestrial ecosystem components of a southern USA mixed pine/hardwood forest. Forest Ecol. Manag. 312:179-192.

Buhlmann, K.A., Pague, C.A., Mitchell J.C., Glasgow R.B., 1988. Forestry operations and terrestrial salamanders: techniques in a study of the Cow Knob Salamander, Plethodon punctatus. In: Szaro, R.C., Severson, K.E., Patton, D.R., (Ed.), Management of amphibians, reptiles, and small mammals in North America. U.S. Forest Service General Technical Report RM-166, Fort Collins, CO, USA, pp 38-44.

Burnham, K.P., Anderson, D.R., Huyvaert, K.P., 2011. AIC model selection and multimodel inference in behavioral ecology: some background, observations, and comparisons. Behav. Ecol. Sociobiol. 65:23-35.

Burton, T.M., Likens, G.E., 1975. Salamander populations and biomass in the Hubbard Brook Experimental Forest, New Hampshire. Copeia 1975:541-546.

Certini, G., 2005. Effects of fire on properties of forest soils: a review. Oecologia 143:1-10.

Cosentino, B.J., Brubaker, K.M., 2018. Effects of land use legacies and habitat fragmentation on salamander abundance. Landsc. Ecol. 33:1573-1584.

Dennis, E.B., Morgan, B.J., Ridout, M.S., 2015. Computational aspects of N-mixture models. Biometrics 71:237-246. 
Downer, H.R., 2009. Distribution of woodland salamanders of the valley and ridge in West Virginia. Thesis, Marshall University, Huntington, WV, USA.

Elliott, K.J., Hendrick, R.L., Major, A.E., Vose, J.M., Swank W.T., 1999. Vegetation dynamics after a prescribed fire in the southern Appalachians. Forest Ecol. Manag. 114:199-213.

Flint, W.D., 2004. Ecology and conservation of the Cow Knob Salamander (Plethodon punctatus). Thesis, James Madison University, Harrisonburg, VA, USA.

Flint, W.D., Harris, R.N., 2005. The efficacy of visual encounter surveys for population monitoring of Plethodon punctatus (Caudata: Plethodontidae). J. Herpetol. 39:578-584.

Ford, W.M., Rodrigue, J.L., Rowan, E.L., Castleberry, S.B., Schuler, T.M., 2010. Woodland salamander response to two prescribed fires in the central Appalachians. Forest Ecol. Manag. 260:1003-1009.

Fontaine, J.B., Kennedy, P.L., 2012. Meta-analysis of avian and small-mammal response to fire severity and fire surrogate treatments in US fire-prone forests. Ecol. Appl. 22:1547-1561.

Gade, M.R., Gould, P.R., Peterman, W.E., 2019. Habitat-dependent responses of terrestrial salamanders to wildfire in the short-term. Forest Ecol. Manag. 449:117479.

Greenberg, C.H., Waldrop. T.A., 2008. Short-term response of reptiles and amphibians to prescribed fire and mechanical fuel reduction in a southern Appalachian upland hardwood forest. Forest Ecol. Manag. 255:2883-2893.

Greenberg, C.H., Seiboldt, T., Keyser, T.L., McNab, W.H., Scott, P., Bush, J., Moorman, C.E., 2018. Reptile and amphibian response to season of burn in an upland hardwood forest. Forest Ecol. Manag. 409:808-816.

Grover, M.C., 1998. Influence of cover and moisture on abundances of the terrestrial salamanders Plethodon cinereus and Plethodon glutinosus. J. Herpetol. 32:489-497. 
Harper, C.A., Ford, W.M., Lashley, M.A., Moorman, C.E., Stambaugh, M.C., 2016. Fire effects on wildlife in the Central Hardwoods and Appalachian regions, USA. Fire Ecol. 12:127159.

Hesed, K.M., 2012. Uncovering salamander ecology: a review of coverboard design. J. Herpetol. 46:442-451.

Highton, R., 1972. Distributional interactions among eastern North American salamanders of the genus Plethodon. Virginia Polytechnic Institute and State University Research Division Monograph 4:139-188.

Hocking, D.J., Connette, G.M., Conner, C.A., Scheffers, B.R., Pittman, S.E., Peterman, W.E., Semlitsch. R.D., 2013. Effects of experimental forest management on a terrestrial, woodland salamander in Missouri. Forest Ecol. Manag. 287:32-39.

Howey, C.A., Roosenburg, W.M., 2013. Effects of prescribed fire on the Eastern Box Turtle (Terrapene carolina carolina). Northeast. Nat. 20:493-498.

Hromada, S.J., Howey, C.A., Dickinson, M.B., Perry, R.W., Roosenburg, W.M., Gienger, C.M., 2018. Response of reptile and amphibian communities to the reintroduction of fire in an oak/hickory forest. Forest Ecol. Manag. 428:1-13.

Kéry, M., Royle, J.A., 2016. Applied hierarchical modeling in ecology: analysis of distribution, abundance and species richness in R and BUGS. Academic Press, Waltham, MA, USA.

Keyser, P.D., Sausville, D.J., Ford, W.M., Schwab, D.J., Brose. P.H., 2004. Prescribed fire impacts to amphibians and reptiles in shelterwood-harvested oak-dominated forests. VA. J. Sci. 55:159-168.

Lafon, C.W., Hoss, J.A., Grissino-Mayer H.D., 2005. The contemporary fire regime of the central Appalachian Mountains and its relation to climate. Phys. Geogr. 26:126-146. 
Lafon, C.W., Grissino-Mayer, H.D., 2007. Spatial patterns of fire occurrence in the central Appalachian Mountains and implications for wildlife fire management. Phys. Geogr. 28:120.

Lafon, C.W., Waldron, J.D., Cairns, D.M., Tchakerian, M.D., Coulson, R.N., Klepzig, K.D., 2007. Modeling the effects of fire on the long-term dynamics and restoration of yellow pine and oak forests in in the southern Appalachian Mountains. Restor. Ecol. $15: 400-411$.

Lafon, C.W., Naito, A.T., Grissino-Mayer, H.D., Horn, S.P., Waldrop, T.A., 2017. Fire history of the Appalachian region: a review and synthesis. Gen. Tech. Rep. SRS-219. USDA, Forest Service, Southern Research Station, Asheville, NC, USA, pp 1-97.

Lashley, M.A., Harper, C.A., Bates, G.E., Keyser, P.D., 2011. Forage availability for whitetailed deer following silvicultural treatments in hardwood forests. J. Wildlife Manage. 75:1467-1476.

Legendre, P., Legendre, L.F., 2012. Numerical ecology (Vol. 24). Elsevier.

Lorber, J., Thomas-Van Gundy, M., Croy, S., 2018. Characterizing effects of prescribed fire on forest canopy cover in the George Washington and Jefferson National Forests. Research Paper NRS-31. USDA Forest Service, Northern Research Station, Newtown Square, PA, USA, pp 1-30.

Maerz, J.C., Nuzzo, V.A., Blossey, B., 2009. Declines in woodland salamander abundance associated with non-native earthworm and plant invasions. Conserv. Biol. 23:975-981.

Margenau, E.L., Crayton, S.M., Rucker, L.E., Jacobsen, C.D., Brown, D.J., 2018. Modified salamander stick to facilitate accurate measurement of small individuals. Herpetol. Rev. 49:243-246. 
Mahoney, K.R., Russell, K.R., Ford, W.M., Rodrigue, J.L., Riddle, J.D., Schuler, T.M., Adams, M.B., 2016. Woodland salamander responses to a shelterwood harvest-prescribed burn silvicultural treatment within Appalachian mixed-oak forests. Forest Ecol. Manag. 359:277-285.

Markle, T.M., Kozak, K.H., 2018. Low acclimation capacity of narrow-ranging thermal specialists exposes susceptibility to global climate change. Ecol. evol. 8:4644-4656.

Matthews, C.E., Moorman C.E., Greenberg C.H., Waldrop, T.A., 2010. Response of reptiles and amphibians to repeated fuel reduction treatments. J. Wildlife Manage. 74:1301-1310.

McCord, J.M., Harper, C.A., Greenberg, C.H., 2014. Brood cover and food resources for wild turkeys following silvicultural treatments in mature upland hardwoods. Wildlife Soc. B. $38: 265-272$.

McCune, B., 1977. Vegetation development on a low elevation talus slope in western Montana. Northwest Sci. 51:198-207.

McCune, B., Keon D., 2002. Equations for potential annual direct incident radiation and heat load. J. Veg. Sci.13:603-606.

Milanovich, J.R., Peterman, W.E., Nibbelink, N.P., Maerz, J.C., 2010. Projected loss of a salamander diversity hotspot as a consequence of projected global climate change. PLoS ONE 5:e12189.

Moore, J.D., 2005. Use of native dominant wood as a new coverboard type for monitoring Eastern Red-backed Salamanders. Herpetol. Rev. 36:268-271.

Nowacki, G.J., Abrams, M.D., 2008. The demise of fire and "mesophication" of forests in the eastern United States. BioScience, 58:123-138. 
O'Donnell, K.M., Semlitsch, R.D., 2015. Advancing terrestrial salamander population ecology: the central role of imperfect detection. J. Herpetol. 49:533-540.

O’Donnell, K.M., Thompson F.R., Semlitsch R.D., 2015. Prescribed fire and timber harvest effects on terrestrial salamander abundance, detectability and microhabitat use. J. Wildlife Manage. 79:766-775.

O’Donnell, K.M., Thompson F.R., Semlitsch R.D., 2016. Prescribed fire alters surface activity and movement behavior of a terrestrial salamander. J. Zool. 298:303-309.

Pérez, F.L., 1998. Conservation of soil moisture by different stone covers on alpine talus slopes (Lassen, California). Catena 33:155-177.

Petranka, J.W., 1998. Salamanders of the United States and Canada. Smithsonian Institution Press. Washington, DC, USA.

Pilliod, D.S., Bury R.B., Hyde E.J., Pearl C.A., Corn P.S. 2003. Fire and amphibians in North America. Forest Ecol. Manag. 178:163-181.

Renken, R.B. 2006. Does fire affect amphibians and reptiles in eastern U.S. oak forests? In: Dickinson, M., (Ed.) Fire in eastern oak forests: delivering science to land managers, proceedings of a conference. General Technical Report NRS P-1, USDA Forest Service, Newton Square, PA, USA, pp 158-166.

Royle, J.A., 2004. N-mixture models for estimating population size from spatially replicated counts. Biometrics 60:108-115.

Schuler, T.M., Van-Gundy, M.T., Adams, M.B., Ford. W.M., 2010. Seed bank response to prescribed fire in the central Appalachians. General Technical Report NRS-9, USDA Forest Service, Newton Square, PA, USA, pp 1-9. 
Schulte-Hostedde, A. I., Zinner, B., Millar, J.S., Hickling, G.J., 2005. Restitution of mass-size residuals: validating body condition indices. Ecology 86:155-163.

Semlitsch, R.D., O'Donnell, K.M., Thompson III, F.R., 2014. Abundance, biomass production, nutrient content, and the possible role of terrestrial salamanders in Missouri Ozark forest ecosystems. Can. J. Zool. 92:997-1004.

Semlitsch, R.D., Ryan, T.J., Hamed, K., Chatfield, M., Drehman, B., Pekarek, N., Spath, M., Watland, A., 2007. Salamander abundance along road edges and within abandoned logging roads in Appalachian forests. Conserv. Biol. 21:159-167.

Symonds, M.R.E., Moussalli. A., 2011. A brief guide to model selection, multimodel inference and model averaging in behavioural ecology using Akaike's information criterion. Behav. Ecol. Sociobiol. 65:13-21.

U.S. Forest Service. 2014. Revised land and resource management plan George Washington National Forest. Management Bull. R8-MB 143A. Roanoke, VA: U.S. Department of Agriculture, Forest Service, Region 8, George Washington National Forest. 374 p.

Van Lear, D.H., Watt. J.M., 1993. The role of fire in oak regeneration. In: Oak regeneration: Serious problems, practical recommendations. General Technical Report SE-84. USDA Forest Service, Asheville, NC, USA, pp 66-78.

Welch, N.T., Waldrop, T.A., Buckner. E.R., 2000. Response of southern Appalachian Table Mountain pine (Pinus pungens) and pitch pine ( $P$. rigida) stands to prescribed burning. Forest Ecol. Manag. 136:185-197.

Zuur, A.F., Ieno, E.N., Walker, N.J., Saveliev, A.A., Smith, G.M., 2009. Mixed effects models and extensions in ecology with R. Springer, New York, NY, USA. 
Table 1. Model selection results to determine relationships between fire history and habitat characteristics on Cow Knob Salamander (Plethodon punctatus) and Red-backed Salamander (Plethodon cinereus) abundance. Geological-topographic model selection variables included state (i.e. West Virginia $=1$, or Virginia $=0$ ), elevation (Elev), slope, hillshade (Hill), Heat Load Index (HLI), an index of talus cover (Talus), and talus or not talus (Bin_tal). Fire history model selection variables included unburned or burned (Burn Status), unburned and severity of burns (Burn Class), and time-since-burn (Time burn). Forest structure model selection variables included canopy cover (C\%), vegetation cover (V\%), leaf cover (L\%), moss cover (M\%), and litter depth in cm (LD). Model selection was based on Quasi Akaike's Information Criterion corrected for small sample size $(\mathrm{QAIC})$.

\begin{tabular}{|c|c|c|c|c|c|c|c|}
\hline \multicolumn{4}{|c|}{ Plethodon punctatus } & \multicolumn{4}{|c|}{ Plethodon cinereus } \\
\hline Model & $\mathrm{QAIC}_{c}$ & $\Delta \mathrm{QAIC}_{c}$ & $\mathrm{w}_{i}$ & Model & $\mathrm{QAIC}_{c}$ & $\Delta \mathrm{QAIC}_{c}$ & $\mathrm{w}_{i}$ \\
\hline Geological models & & & & Geological models & & & \\
\hline Bin_tal + WV & 243.26 & 0 & 0.55 & State & 350.07 & 0.00 & 0.35 \\
\hline Bin_tal + Elev & 244.41 & 1.15 & 0.31 & State + Talus & 350.34 & 0.27 & 0.30 \\
\hline Bin_tal & 247.39 & 4.14 & 0.07 & State + Slope & 351.34 & 1.27 & 0.18 \\
\hline Talus & 248.81 & 5.55 & 0.03 & State + Bin_tal & 352.05 & 1.98 & 0.13 \\
\hline Bin_tal + Slope & 249.94 & 6.69 & 0.02 & Hill & 355.09 & 5.02 & 0.03 \\
\hline WV & 251.03 & 7.77 & 0.01 & Talus & 357.71 & 7.64 & 0.01 \\
\hline Elev & 252.81 & 9.55 & 0 & Bin_tal & 359.82 & 9.75 & 0.00 \\
\hline HLI & 256.09 & 12.83 & 0 & Slope & 362.16 & 12.09 & 0.00 \\
\hline Slope & 258.48 & 15.22 & 0 & Elev & 369.30 & 19.23 & 0.00 \\
\hline Hill & 258.88 & 15.62 & 0 & State + Elev & 395.50 & 45.43 & 0.00 \\
\hline Fire History Models & & & & Fire history models & & & \\
\hline Bin_tal + State + Burn & 239.04 & 0 & 0.62 & State & 330.38 & 0.00 & 0.47 \\
\hline Bin_tal + State & 240.03 & 1 & 0.38 & State + Burn Class & 331.05 & 0.67 & 0.34 \\
\hline Burn site-only models & & & & State + Burn Status & 332.24 & 1.86 & 0.19 \\
\hline Bin_tal & 141.16 & 0.00 & 0.84 & Burn site-only models & & & \\
\hline Bin_tal + Time burn & 144.53 & 3.37 & 0.16 & Hill & 163.31 & 0.00 & 0.77 \\
\hline Forest structure Models & & & & Hill + BurnT & 165.72 & 2.41 & 0.23 \\
\hline Bin_tal + State + C\% & 244.57 & 0.00 & 0.30 & Forest structure models & & & \\
\hline Bin_tal + State & 244.90 & 0.34 & 0.25 & State $+\mathrm{C} \%+\mathrm{V} \%$ & 340.95 & 0.00 & 0.24 \\
\hline Bin_tal + State $+\mathrm{C} \%+\mathrm{V} \%$ & 247.06 & 2.50 & 0.09 & State $+\mathrm{C} \%$ & 341.09 & 0.14 & 0.22 \\
\hline Bin_tal + State $+C \%+$ LD & 247.18 & 2.61 & 0.08 & State $+C \%+L D$ & 342.33 & 1.38 & 0.12 \\
\hline Bin_tal + State $+\mathrm{C} \%+\mathrm{L} \%$ & 247.26 & 2.69 & 0.08 & State + C\% + V\% + LD & 342.48 & 1.53 & 0.11 \\
\hline Bin_tal + State + LD & 247.51 & 2.95 & 0.07 & State $+\mathrm{C} \%+\mathrm{V} \%+\mathrm{M} \%$ & 343.26 & 2.30 & 0.08 \\
\hline Bin_tal + State + L\% & 247.54 & 2.97 & 0.07 & State $+\mathrm{C} \%+\mathrm{M} \%$ & 343.60 & 2.65 & 0.06 \\
\hline Bin_tal + State + V\% & 247.54 & 2.97 & 0.07 & State $+\mathrm{C} \%+\mathrm{L} \%$ & 343.74 & 2.79 & 0.06 \\
\hline \multirow[t]{6}{*}{ Bin_tal + State + C $\%$} & 244.57 & 0.00 & 0.30 & State $+\mathrm{C} \%+\mathrm{V} \%+\mathrm{L} \%$ & 343.78 & 2.83 & 0.06 \\
\hline & & & & State & 346.31 & 5.36 & 0.02 \\
\hline & & & & State + LD & 347.59 & 6.63 & 0.01 \\
\hline & & & & State $+M \%$ & 348.22 & 7.27 & 0.01 \\
\hline & & & & State $+\mathrm{L} \%$ & 348.78 & 7.83 & 0.00 \\
\hline & & & & State $+V \%$ & 348.79 & 7.84 & 0.00 \\
\hline
\end{tabular}


Table 2. Abundance parameter estimates $(\beta)$ for the best approximating fire history and forest structure $N$-mixture models for the Cow Knob Salamander (Plethodon punctatus; left) and the Eastern Red-Backed Salamander (Plethodon cinereus; right). Variables include state (West Virginia or Virginia), an index of talus cover (Talus), talus or not talus (Bin_tal), canopy cover (C\%), vegetation cover (V\%), litter depth (LD), unburned or burned (Burn Status), and burn class (i.e. unburned, low-severity [Low] or high-severity [High]).

\begin{tabular}{lclllllll}
\hline & \multicolumn{3}{c}{ Plethodon punctatus } & \multicolumn{5}{c}{ Plethodon cinereus } \\
Variable & $\beta$ & SE & $95 \%$ CI & Variable & $\beta$ & SE & $95 \%$ CI \\
\hline Fire history model & & & & Fire history model & & & \\
(Intercept) & 0.899 & 1.257 & $(-1.56,3.36)$ & (Intercept) & 2.116 & 0.694 & $(0.76,3.48)$ \\
Bin_Tal & 1.333 & 0.416 & $(0.52,2.15)$ & State & 0.669 & 0.183 & $(0.30,1.03)$ \\
State & 1.146 & 0.334 & $(0.49,1.80)$ & High & -1.048 & 0.488 & $(-2.00,-0.09)$ \\
Burn Status & -0.612 & 0.264 & $(-1.13,-0.09)$ & Low & -0.047 & 0.149 & $(-0.34,0.25)$ \\
Forest structure model & & & & Forest structure model & & & \\
(Intercept) & 0.655 & 1.133 & $(-1.57,2.88)$ & (Intercept) & -0.716 & 1.302 & $(-3.27,1.84)$ \\
Bin_Tal & 1.439 & 0.421 & $(0.62,2.26)$ & State & 0.891 & 0.183 & $(0.53,1.25)$ \\
State & 0.714 & 0.360 & $(0.01,1.42)$ & C\% & 0.036 & 0.010 & $(0.02,0.05)$ \\
C\% & 0.031 & 0.016 & $(-0.00,0.06)$ & V\% & 0.007 & 0.003 & $(0.00,0.01)$ \\
\hline
\end{tabular}


Table 3. Model selection results for relationships between habitat variables and body condition index (BCI) for the Cow Knob Salamander (Plethodon punctatus; left) and Eastern Red-Backed Salamander (Plethodon cinereus; right). Geological-topographic model selection variables included state (West Virginia or Virginia), an index of talus cover (Talus), elevation (Elev), slope, hillshade (Hill), and Heat Load Index (HLI). Fire history model selection variables included unburned or burned (Burn Status). Forest structure model selection variables included canopy cover (C\%), vegetation cover (V\%), leaf cover (L\%), moss cover (M\%), and litter depth (LD). Model selection was based on Quasi Akaike's Information Criterion corrected for small sample size $\left(\mathrm{AIC}_{c}\right)$.

\begin{tabular}{|c|c|c|c|c|c|c|c|}
\hline \multicolumn{4}{|c|}{ Plethodon punctatus } & \multicolumn{4}{|c|}{ Plethodon cinereus } \\
\hline Model & $\mathrm{AIC}_{c}$ & $\Delta \mathrm{AIC}_{c}$ & $\mathrm{~W}_{i}$ & Model & $\mathrm{AIC}_{c}$ & $\Delta \mathrm{AIC}_{c}$ & $\mathrm{w}_{i}$ \\
\hline Geological Models & & & & Geological Models & & & \\
\hline State & -108.91 & 0.00 & 0.28 & State & -124.14 & 0.00 & 0.28 \\
\hline State + HLI & -108.69 & 0.22 & 0.25 & Null & -122.67 & 1.47 & 0.13 \\
\hline State + Talus & -107.36 & 1.55 & 0.13 & State + HLI & -122.61 & 1.53 & 0.13 \\
\hline State + Hill & -106.77 & 2.14 & 0.10 & State + Hill & -122.20 & 1.94 & 0.11 \\
\hline State + Elev & -106.56 & 2.35 & 0.09 & State + Talus & -122.04 & 2.10 & 0.10 \\
\hline HLI & -106.07 & 2.83 & 0.07 & State + Elev & -121.94 & 2.20 & 0.09 \\
\hline Null & -105.10 & 3.80 & 0.04 & HLI & -121.52 & 2.62 & 0.07 \\
\hline Talus & -103.56 & 5.35 & 0.02 & Elev & -120.57 & 3.57 & 0.05 \\
\hline Hill & -103.47 & 5.43 & 0.02 & Talus & -120.52 & 3.62 & 0.05 \\
\hline Elev & -103.03 & 5.88 & 0.01 & Fire history models & & & \\
\hline Fire-history Models & & & & State & -124.14 & 0.00 & 0.64 \\
\hline State & -108.91 & 0.00 & 0.77 & State + Burn Status & -123.02 & 1.12 & 0.36 \\
\hline State + Burn Status & -106.53 & 2.37 & 0.23 & Forest structure models & & & \\
\hline Forest structure models & & & & State $+\mathrm{V} \%+\mathrm{L} \%+\mathrm{LD}$ & -133.03 & 0.00 & 0.32 \\
\hline State + LD & -108.93 & 0.00 & 0.18 & State + V\% + L\% & -132.68 & 0.35 & 0.27 \\
\hline State & -108.91 & 0.02 & 0.18 & State $+\mathrm{V} \%$ & -130.79 & 2.24 & 0.10 \\
\hline State + V\% & -108.54 & 0.38 & 0.15 & State + V\% + L\% + M\% & -130.73 & 2.30 & 0.10 \\
\hline State + LD + V\% & -108.44 & 0.48 & 0.14 & State $+\mathrm{V} \%+\mathrm{L} \%+\mathrm{C} \%$ & -130.32 & 2.71 & 0.08 \\
\hline State + Can & -107.43 & 1.50 & 0.08 & State $+\mathrm{V} \%+\mathrm{M} \%$ & -128.69 & 4.33 & 0.04 \\
\hline State + LD + C\% & -106.88 & 2.05 & 0.06 & State + V\% + LD & -128.69 & 4.34 & 0.04 \\
\hline State + L\% & -106.74 & 2.18 & 0.06 & State $+\mathrm{V} \%+\mathrm{C} \%$ & -128.62 & 4.41 & 0.04 \\
\hline State $+M \%$ & -106.59 & 2.33 & 0.06 & State & -124.14 & 8.89 & 0.00 \\
\hline State + L\% + LD & -106.45 & 2.48 & 0.05 & State + M\% & -123.87 & 9.16 & 0.00 \\
\hline State + LD + M\% & -106.45 & 2.48 & 0.05 & State $+\mathrm{L} \%$ & -123.22 & 9.80 & 0.00 \\
\hline & & & & State + LD & -122.54 & 10.49 & 0.00 \\
\hline
\end{tabular}


Table 4. Parameter estimates ( $\beta$ ) for relationships between habitat variables and body condition index (BCI) for the Cow Knob Salamander (Plethodon punctatus; left) and Eastern Red-Backed Salamander (Plethodon cinereus; right). Geological-topographic variables include state (West Virginia or Virginia) and slope, fire history variables include unburned or burned (Burn Status), and forest structure variables include vegetation cover (V\%), leaf cover (L\%), and litter depth (LD).

\begin{tabular}{lccclcccc}
\hline \multicolumn{3}{l}{ Plethodon punctatus } & \multicolumn{5}{c}{ Plethodon cinereus } \\
Variable & $\beta$ & SE & $95 \%$ CI & Variable & $\beta$ & SE & $95 \%$ CI \\
\hline Fire history model & & & & Fire history model & & & \\
Intercept & -0.072 & 0.033 & $(-0.10,0.30)$ & Intercept & 0.045 & 0.024 & $(-0.00,0.09)$ \\
State & 0.083 & 0.034 & $(0.01,0.14)$ & State & -0.047 & 0.027 & $(-0.10,0.00)$ \\
Burn Status & -0.001 & 0.022 & $(-0.04,0.04)$ & Burn Status & -0.025 & 0.024 & $(-0.07,0.02)$ \\
Forest structure model & & & & Forest structure model & & & \\
Intercept & -0.049 & 0.034 & $(-0.11,0.02)$ & Intercept & 0.124 & 0.031 & $(0.06,0.18)$ \\
State & 0.086 & 0.033 & $(0.02,0.15)$ & State & -0.035 & 0.028 & $(-0.09,0.02)$ \\
LD & -0.042 & 0.028 & $(-0.10,0.01)$ & V\% & -0.002 & 0 & $(-0.00,-0.00)$ \\
& & & & L\% & -0.002 & 0.001 & $(-0.00,-0.00)$ \\
& & & & LD & 0.094 & 0.058 & $(-0.02,0.20)$ \\
\hline
\end{tabular}




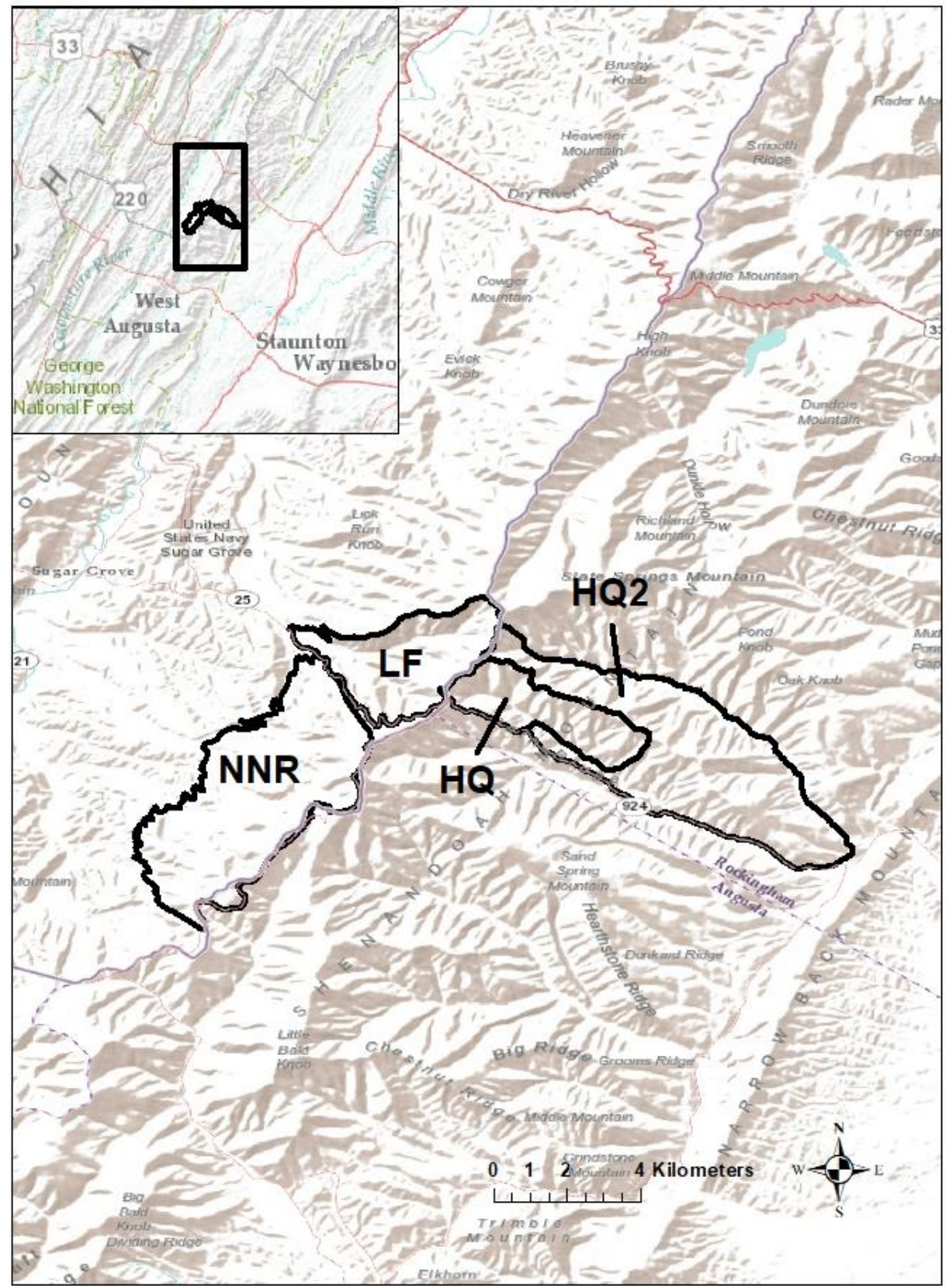

Fig. 1. Burn units included in this study investigating responses of woodland salamanders to prescribed fire management on Shenandoah Mountain in the George Washington National Forest in West Virginia and Virginia, USA. Prescribed burns were conducted in the following years: North New Road (NNR) in 2012 and 2015, Little Fork (LF) in 2000 and 2008, Hone Quarry (HQ) in 1999, 2002, 2010, 2013, and 2018, and Hone Quarry 2 (HQ2) in 2013 and 2018. 

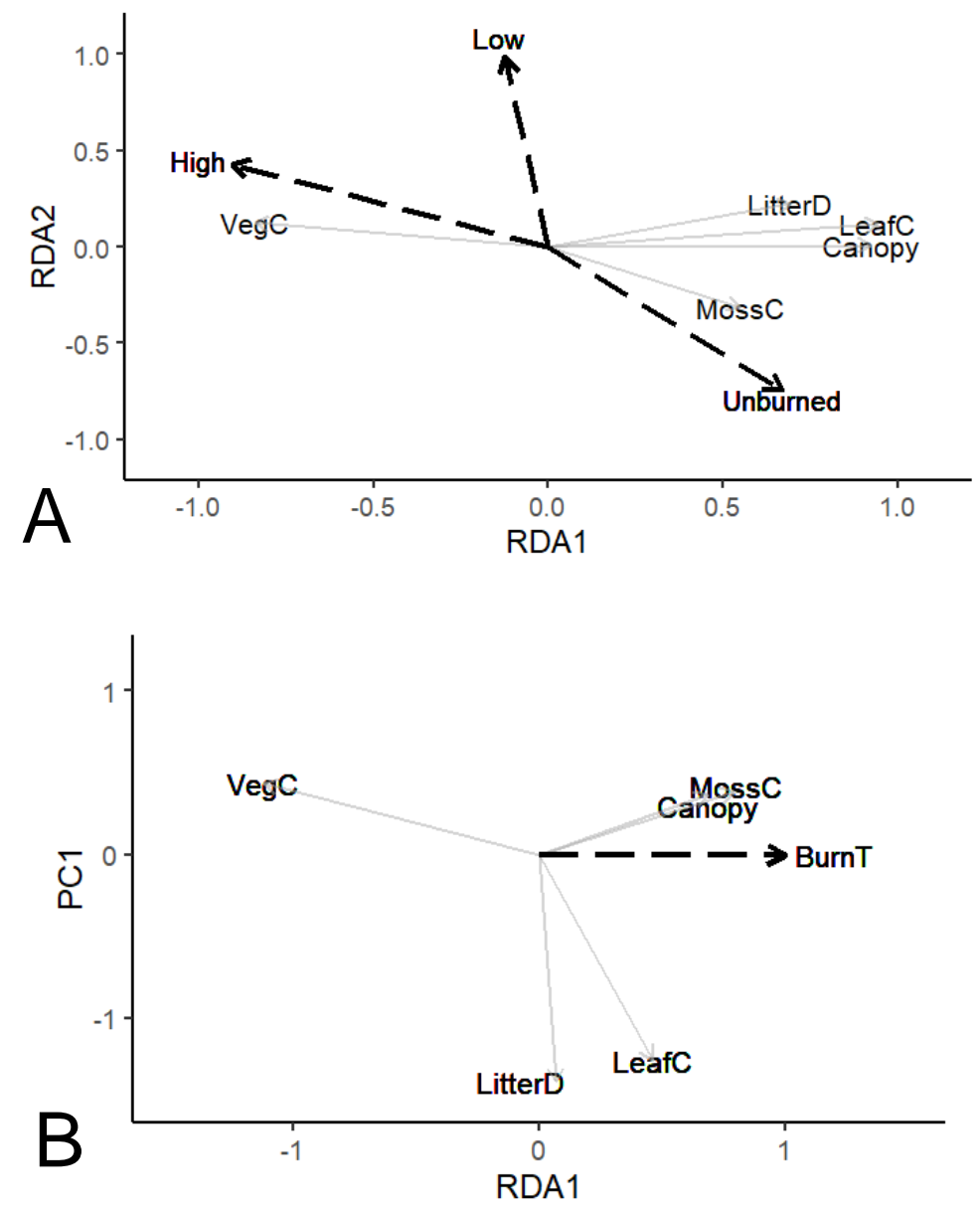

Fig. 2. Biplots from redundancy analyses (RDA) showing the relationships between forest structure characteristics and fire history variables at our woodland salamander survey plots on Shenandoah Mountain in the George Washington National Forest in West Virginia and Virginia, USA. Forest structure characteristics included canopy cover \% (Canopy), moss cover \% (MossC), vegetation cover \% (VegC), leaf cover \% (LeafC), and leaf litter depth (LitterD). (A) Relationships between forest structure characteristics and whether a site was located in the unburned, low-severity (Low), or high-severity (High) burn class. (B) Relationships between forest structure characteristics and time-since-burn (BurnT) among the burn sites. Forest structure characteristics pointing towards the fire history variables were positively correlated, and vice versa. 

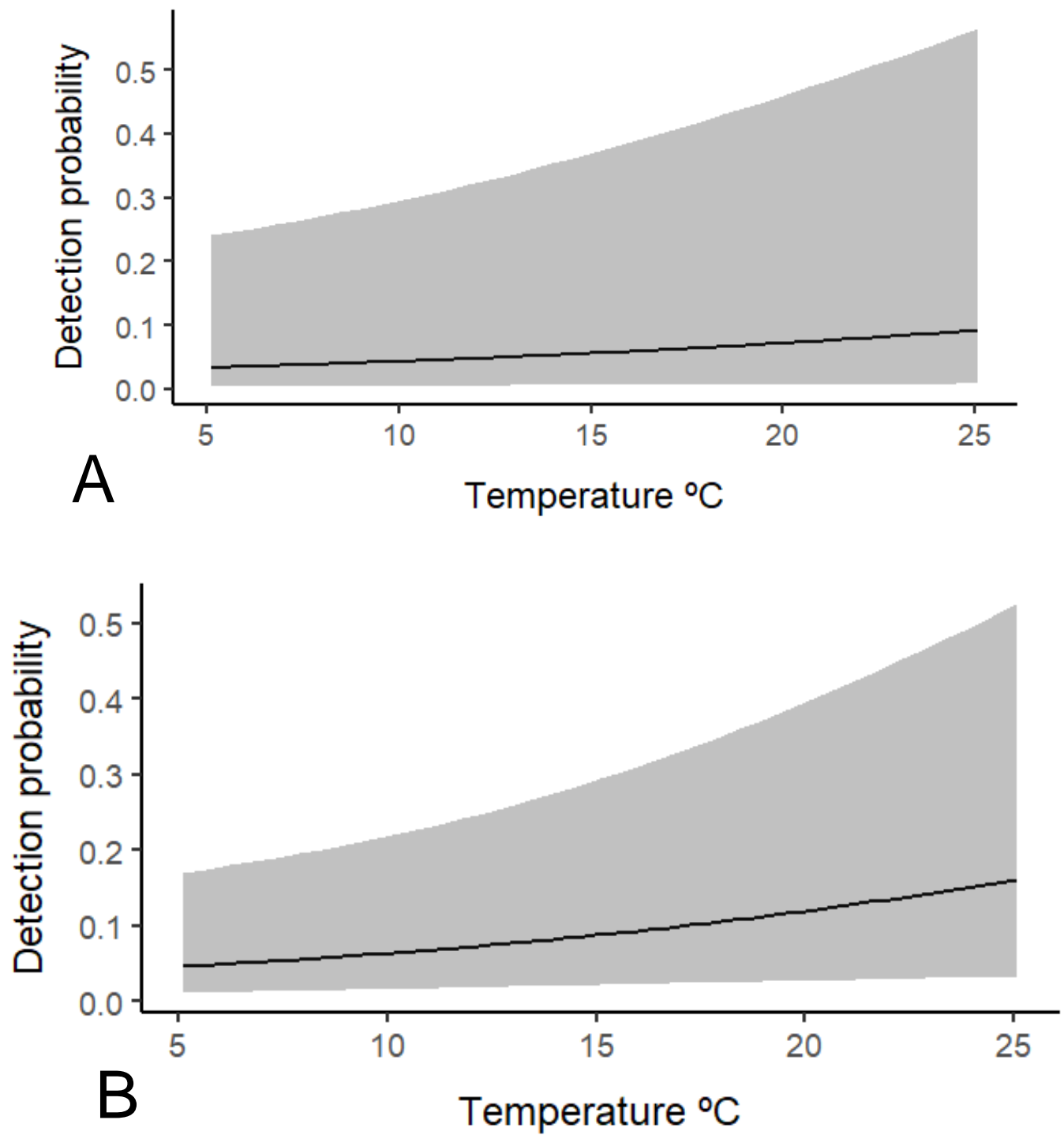

Fig. 3. Estimated relationship between air temperature and detection probability ( $p$ ) for (A) the Cow Knob Salamander (Plethodon punctatus), and (B) the Eastern Red-Backed Salamander (Plethodon cinereus) on Shenandoah Mountain in the George Washington National Forest. These $p$ estimates are based on $N$-mixture models that included 197 surveys across 61 sites in 2017 and 2018, abundance predictors were (West Virginia or Virginia), talus or not talus, and canopy cover (\%) for $P$. punctatus and state, canopy cover (\%), and vegetation cover (\%) for $P$. cinereus. The black line represents mean detection probability and gray areas fall within the $95 \%$ confidence interval. 

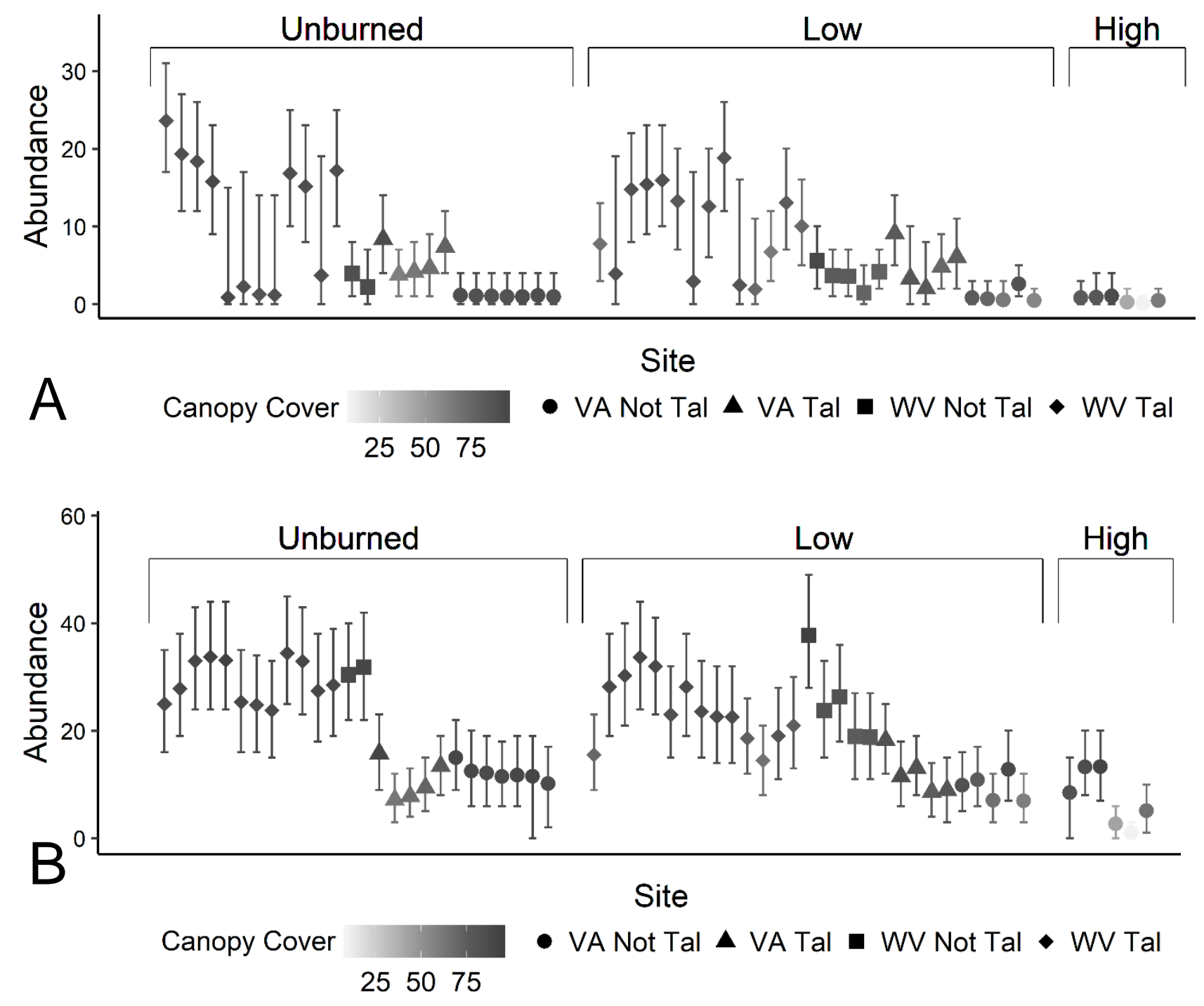

Fig. 4. Estimated abundances of (A) the Cow Knob Salamander (Plethodon punctatus) and (B) the Eastern Red-backed Salamander (Plethodon cinereus) across 61, $25 \mathrm{~m}^{2}$ sites surveyed in 2017 or 2018 on Shenandoah Mountain in the George Washington National Forest in West Virginia and Virginia, USA. Abundance estimates are based on $\mathrm{N}$-mixture models using geological-topographic and forest structure predictors-only, including the additive effects of state (West Virginia or Virginia), talus or not talus, and canopy cover (\%) for P. punctatus, and state, canopy cover (\%), and vegetation cover (\%) for P. cinereus. Site abundances are separated by burn class (unburned, low-severity [Low], and high-severity [High]). Shapes represent the mean 
abundance estimate for the following sites: circles for VA not talus, triangles for VA talus, squares for WV not talus, and diamonds for WV talus. Lines represent $95 \%$ confidence intervals. Shading represents a site's canopy cover, with lighter shading represents less canopy cover and darker shading represents more canopy cover. 

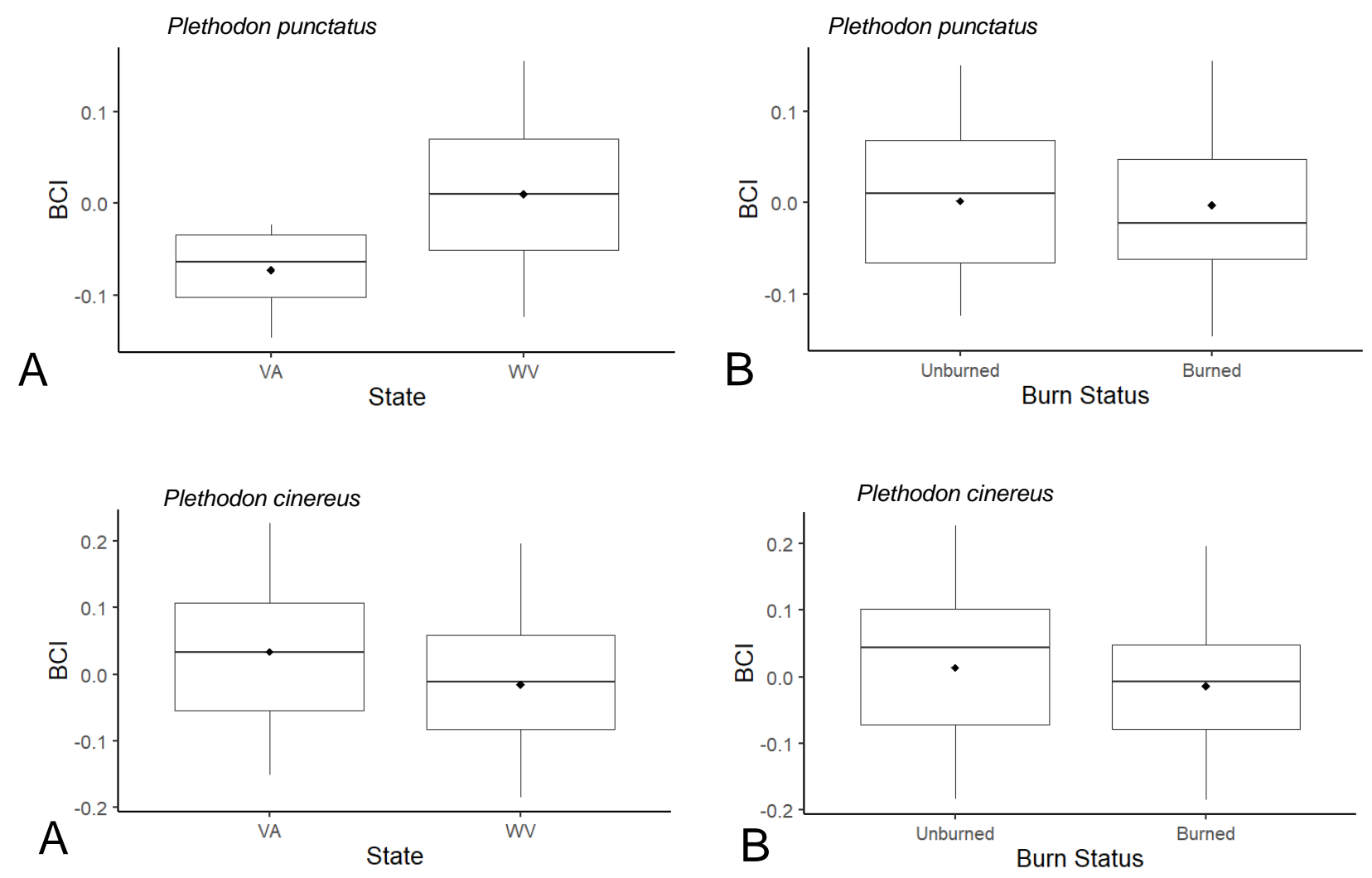

Fig. 5. Boxplot summaries of body condition index (BCI) values from our study investigating responses of woodland salamanders to prescribed fire management on Shenandoah Mountain in the George Washington National Forest in West Virginia and Virginia, USA. We found BCI for the Cow Knob Salamander (Plethodon punctatus; $\mathrm{n}=49$; top) was (A) higher on the West Virginia side of the mountain, and (B) some support BCI is higher in unburned areas. For the Eastern Red-Backed Salamander (Plethodon cinereus; $\mathrm{n}=76$; bottom) BCI was (A) lower on the West Virginia side of the mountain and (B) Some support that BCI is higher in unburned areas. 